\title{
Improvement of Mode I Interlaminar Fracture Toughness of Stitched Glass/Epoxy Composites
}

\author{
D. Göktaş ${ }^{1}$ - W. R. Kennon ${ }^{1} \cdot$ P. Potluri ${ }^{1}$
}

Received: 29 September 2016 / Accepted: 31 October 2016/Published online: 21 November 2016

C The Author(s) 2016. This article is published with open access at Springerlink.com

\begin{abstract}
This study examines the improvement of Interlaminar Fracture Toughness (IFT) of multilayered 3D glass/epoxy textile composites when through thickness reinforcement is introduced. Three stitching techniques have been examined: Modified Lockstitch (ISO-301), Single-yarn Orthogonal-stitch (ISO-205) and Double-yarn Orthogonal-stitch (ISO-205). It was found that the use of class ISO-205 manual-type stitched reinforcement significantly enhanced the Mode I-IFT, $\mathrm{G}_{\mathrm{IC}}$ measured using a Double Cantilever Beam technique. Furthermore, in every case, the use of class ISO-205 stitching and high stitch densities offer a significant improvement of $74.5 \%$ on Mode I-IFT against interlaminar delamination.
\end{abstract}

Keywords Mode I interlaminar fracture toughness · Delamination resistance · Stitching · Glass/ epoxy composite

\section{Introduction}

Fibre reinforced textile composite materials generally comprise a number of layers of 2D textile fabrics. Because of their weak through thickness mechanical properties, they suffer significant interlaminar delamination when exposed to out of plane loading [1, 2]. As part of the research into the in-plane mechanical properties of multilayered textile composites, numerous studies have been carried out by researchers in recent years [3, 4].

To provide through thickness reinforcement, braiding, knitting, 3D weaving, and stitching have been used to improve the interlaminar crack (delamination) resistance of multilayered composites. Among these reinforcement techniques, researchers have concluded that stitching is an effective reinforcement technique to limit crack propagation and to minimise delamination within multilayered textile composites [3-10]. The awareness of stitching as a technique for through thickness reinforcement has increased rapidly during the last three decades.

\section{W. R. Kennon}

richard.kennon@manchester.ac.uk 
In this study, class ISO-205, a Single-yarn Orthogonal-stitch (SOS) and a Double-yarn Orthogonal-stitch (DOS) technique have been used to obtain through thickness reinforcement and these differ from the stitching techniques that have been previously utilised for this task; Modified Lockstitch (ISO-301), Lockstitch(ISO-301) and Chain Stitch (ISO-101) as reported by Morales in 1990 [11]. These commonly-used reinforcement stitching techniques are shown in Fig. 1, and were subsequently re-examined by Dransfield [3].

Both the lockstitch and the modified lockstitch require two constituent threads. The needle thread is inserted through the top of the fabric via the sewing needle, even as the under-thread is supplied from beneath the fabric via a bobbin. The two stitch yarns are first interlaced and then pulled into position in the middle of the fabric layers in the through thickness direction throughout the configuration of the balanced lockstitch. This formation damages the fabric fibres around the stitch loop and may trigger a high stress concentration point [11]. To avoid this problem the lockstitch is generally modified when used for textile composite preforms by diminishing the tension of the bobbin yarn (by loosening the bobbin-case spring), and also by increasing of the needle yarn, by increasing the pressure applied on the needle thread by the tension-disc adjuster. This readjustment of the stitch balance brings the interlace point to the top surface of the preform $[11,13]$. Thus, the geometry of the lockstitch may be modified to ease the stress concentration and to address the problem stated above; this stitch form is almost universally used in composite applications. This stitching technique usefully halves the number of small-radius loops in the sewing thread from two per stitch to just one.

In contrast to these two stitch forms, the ISO-101 chain stitch is intralooped and only involves one yarn to complete the stitch formation process. It is very similar in structure to the weft knitting process, as it uses one single stitch yarn constantly making loops around itself [11]. Nevertheless, because small radius loops of $360^{\circ}$ are required in the formation of every stitch and these are held during stitching by an under-bed looper, the flexibility demanded of the stitching yarn for this stitch geometry makes it inconvenient for advanced fibre yarns such as carbon, Kevlar and glass [3].

The alternative SOS and DOS techniques which have been used in this study are structurally simpler than the traditionally-used lockstitching techniques and moreover the theoretical stitch formation does not require any angles to be made in the yarn of greater than $90^{\circ}$. In practice, because of the flexibility and compressibility of the fabric layers being sewn, the bending of the stitching yarn is further minimised in radius. The orthogonal seam can therefore be created using high-performance (stiff) fibre yarns. Further critical characteristics of the SOS and DOS techniques are that an equal distance is left between successive needle penetration

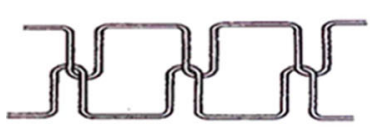

a Lockstitch (ISO 301)

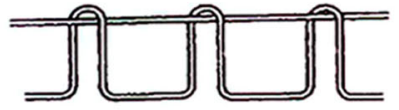

b Modified Lockstitch (Unbalanced LockstitchISO 301)

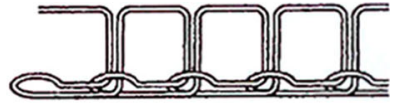

C Chain Stitch (ISO 101)

Fig. 1 Typical stitch types used for through-thickness reinforcement; (a) Lockstitch, (b) Modified Lockstitch, (c) Chain Stitch $[11,12]$ 
points and the stitching yarn is laid on both sides of the fabric preform; therefore the fabric is stabilised with even tensions applied above and below.

\subsection{The Effects of Stitching on the Mechanical Properties of Multilayered Composites}

The stitching technique as a through thickness reinforcement for multilayered textile composite structures has been mainly used by researchers in their experimental studies $[8-10,14,15]$. To stitch the laminates, especially high strength yarns frequently made of carbon, Kevlar, and glass have been used. Many studies have shown that stitching is the most effective through thickness reinforcement technique for composite preforms, even if many studies differ from each other with reference to fabric structure, fibre orientation, resin type, stitch density, direction of stitching, stitching yarn, stitch tension, and stitch patterns utilised. To limit interlaminar delamination and to achieve high delamination resistance many experimental studies on multilayered textile composite materials using the Double Cantilever Beam technique (DCB) test method have been carried out. These studies show that stitching the laminates results in a conspicuous enhancement of the Mode I-IFT, $\mathrm{G}_{\mathrm{IC}}$ in comparison with unstitched composite laminates $[1,3-10,13,16]$. The researchers have stated that the introduction of through thickness stitching has increased the Mode II-IFT performance of multilayered textile composites and likewise the Mode I-IFT is also enhanced [1, 17-20].

Most studies confirm that stitching the laminates had not altered the impact damage resistance even though through thickness stitching has been shown to improve impact damage resistance [21]. Liu's findings [22] show that stitching enhances the interlaminar strength and diminishes the damage area. The delamination resistance was inspected with respect to the effectiveness of various stitch patterns and across a variety of stitch densities. Liu pointed out [22] that stitching impedes the propagation of delamination and reduces the delamination area in accordance with the increase of stitch density.

Sharma and Shankar [19] concluded that stitching of laminates did not have a significant effect on the impact damage resistance, but decreased the damage area and increased the compression strength after impact, whilst Kang and Lee [23] found that the impact resistance properties had been improved by stitching the textile composite laminates.

Some studies show that stitching enhances or has no effect on flexural strength [1]. According to Kang and Lee [23], the tensile and flexural properties of woven laminate composites were improved by stitching. However, Mouritz [14] found that the stitching of glass reinforced polymer (GRP) laminates lessened the flexural properties. Moreover, it was found that these reductions were caused by the damage introduced by the stitching process, creation of resin-rich areas at the stitch holes, breakage of glass fibres, and also stitch interlacements. Even though stitching increased the elastic modulus, it did not affect the flexural and yield strengths [14].

In this study, the MLS, SOS and DOS stitching techniques have been used for the through thickness reinforcement of glass fibre fabric preforms. In total, five different stitch densities have been applied to multilayered preforms using these three stitching techniques. Hence, the effect of different stitching techniques and different stitch densities have been examined for stitched glass/ epoxy composite specimens and compared to unstitched (UNS) composite specimens. 


\section{Experimental}

\subsection{Materials and Preparation of Preform Panels}

In this study, it was chosen to use 8 layers of $2 \times 2$ twill weave structure made from E-glass fabric supplied by Sigmatex Ltd UK [24], having an a real weight of $876 \mathrm{~g} / \mathrm{m}^{2}$ and with $2.54 \mathrm{~g} /$ $\mathrm{cm}^{3}$ E-glass fibre density [25] and this was integrated into a single preform panel to provide a test specimen thickness between 3 and $5 \mathrm{~mm}$, in accordance with the ASTM D5528-01 standard test method [26]. All fabric layers were laid in the warp direction with dimensions of $390 \mathrm{~mm}$ (width) x $320 \mathrm{~mm}$ (length). The stitching process was performed (and will be explained in detail in the following section) after layering the eight plies of fabric. Following the completion of the stitching process, 12 extra layers of unidirectional (UD) E-glass fabric supplied by Formax with $498 \mathrm{~g} / \mathrm{m}^{2}+/-5 \%$ fabric density and $2.54 \mathrm{~g} / \mathrm{cm}^{3}$ E-glass fibre density [25] was used to obtain an increment for the final thickness of the test specimens. Even though international standards were followed wherever appropriate, this modification was made because, during initial testing of the trial set of composite specimens, the test malfunctioned; part of the test specimens fractured before the delamination part of the process had been completed. It was realised that the standard (ASTM) thickness of the trial set of test specimens was inadequate for the delamination process to be completed. It was found that for all the DCB test specimens, either the top or bottom arm bent severely without the first stitch being broken. Additionally, many of the loading hinges became detached as shown in Fig. 2, although this problem did not effect the entire range of composite test specimens used in this work.

Supplementary UD E-glass fabric plies were added to both sides of the pre-prepared preform panels; 6 plies of UD were added on top and six plies beneath. Therefore, the thickness of the test specimens was almost doubled (with a commensurate increase in stiffness) in order to gain a final thickness of the test specimens which allowed the test to be accomplished correctly [26]. The preform panel fabric specifications are given in Table 1.

\subsection{Through Thickness Reinforcement - the Stitching Process}

Following the preparation of preform panels, the Mode I-DCB test specimens were marked with the dimensions as required by the DCB testing standard in $25 \mathrm{~mm}$ (width) $\mathrm{x} 125 \mathrm{~mm}$ (length) on the preform panels. While marking the test specimens, $62 \mathrm{~mm}$ was retained as the working length for the stitching area and $63 \mathrm{~mm}$ of the specimens were separated by inserting Teflon film to separate the initial delamination length $\left(a_{0}\right)$ of the test samples. To reinforce the

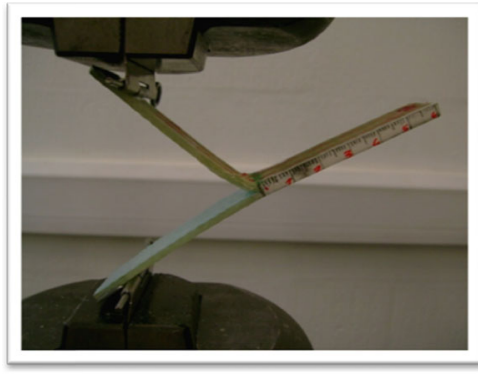

a

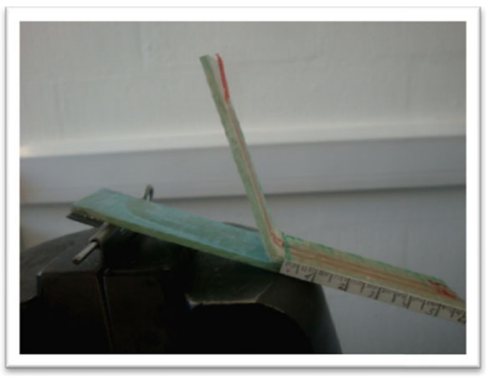

b

Fig. 2 a The top arm of the test specimen bent during the trial. b Detachment of metal hinge during testing 
Table 1 Specifications of fabrics used in preform panels

\begin{tabular}{lll}
\hline & Twill fabric & UD fabric \\
\hline Fabric type & E-glass & E-glass \\
Fabric structure & $2 \times 2$ twill weave & Unidirectional \\
Areal density of fabric & $876 \mathrm{~g} / \mathrm{m}^{2}$ & $498 \mathrm{~g} / \mathrm{m}^{2} \pm 5 \%$ \\
Density of fibre & $2.54 \mathrm{~g} / \mathrm{cm}^{3}$ & $2.54 \mathrm{~g} / \mathrm{cm}^{3}$ \\
Yarn linear density & $1200 \mathrm{Tex}$ & $1200 \mathrm{Tex}$ \\
One layer fabric thickness & $1.3 \mathrm{~mm}$ & $1.1 \mathrm{~mm}$ \\
\hline
\end{tabular}

preform panels the through thickness stitching method was introduced in the z-direction. Five different stitch densities were created by using a number of different stitch lengths: 20, 10, and $5 \mathrm{~mm}$, inserted vertically in a single column through the length of the specimen; the yarns are specified in Table 2 . Stitch patterns of: $10 \times 10$ and $5 \times 5 \mathrm{~mm}$ were also inserted vertically and horizontally in two columns as shown in Table 4 . The different stitch types being compared in the experimental work were inserted into the preform panel at the marked needle insertion points, so that the three stitching techniques could be compared in an unbiased fashion. The first stitching technique to be inserted was the commonly used MLS, the second technique was SOS, and the third was DOS.

\subsubsection{Modified Lockstitch (MLS)}

The commonly-used MLS (ISO-301) stitch technique was applied to the preform panels in the through thickness direction, as the first stitching procedure to be performed on an ADLER: KL267 type sewing machine. This sewing machine is designed to create a standard lockstitch seam using heavy gauge thread and is particularly well-suited to use in the automotive and upholstery industrial sectors [12]; the needle thread tension was increased and the bobbin thread tension decreased so that it would generate a modified lock-stitch. For the needle yarn, nylon 6.6 of $0.5 \mathrm{~mm}$ diameter was used as a top thread which was implemented to lock the stitches on the surface of the laminate. For the bobbin yarn, $0.6 \mathrm{~mm}$ diameter E-glass was used as the bottom thread which was implemented for through thickness reinforcement inside the

Table 2 Specifications of stitching yarns and stitching techniques used in sample preparation

\begin{tabular}{|c|c|c|c|}
\hline Stitching techniques & MLS & SOS & DOS \\
\hline Stitching yarn type & $\begin{array}{l}\text { Needle Yarn: } \\
\text { nylon } 6.6 \\
\text { (Z-twisted-3ply) } \\
50 \text { tex } \\
0.5 \mathrm{~mm} \text { single yarn diameter } \\
\text { Bobbin Yarn: } \\
\text { E-glass Yarn } \\
\text { (S-twisted-2ply) } \\
272 \text { tex } \\
0.6 \mathrm{~mm} \text { single yarn diameter }\end{array}$ & $\begin{array}{l}\text { Single E-glass Yarn } \\
\quad \text { (S-twisted-2ply) } \\
272 \text { tex } \\
0.6 \mathrm{~mm} \\
\text { single yarn diameter }\end{array}$ & $\begin{array}{l}\text { Double E-glass Yarn } \\
\quad \text { (S-twisted-2ply) } \\
272 \text { tex } \\
0.6 \mathrm{~mm} \\
\text { single yarn diameter }\end{array}$ \\
\hline Stitch type & ISO-301 (machine) & ISO-205 (manually) & ISO-205 (manually) \\
\hline Needle specs. & $1.10 \mathrm{~mm}$ (round point) & $1.10 \mathrm{~mm}$ (round point) & $1.10 \mathrm{~mm}$ (round point) \\
\hline
\end{tabular}


laminates as is shown in the sketch in Fig. 3 which illustrates the cross section of the MLS stitch geometry.

\subsubsection{Single-yarn Orthogonal-stitch (SOS)}

The "Single-yarn Orthogonal-stitch" (ISO-205) is an alternative stitch geometry which has been named the SOS technique. It was applied to the preform panels as through thickness reinforcement by hand [12] at this stage. The SOS technique was applied with precisely defined stitch lengths using single $0.6 \mathrm{~mm}$ diameter E-glass yarn with identical stitch spacing to that of the MLS technique as illustrated in Fig. 4 which shows the cross section of the SOS stitch geometry.

\subsubsection{Double-yarn Orthogonal-stitch (DOS)}

The "Double-yarn Orthogonal-stitch" (ISO-205) offers an alternative stitch geometry and was named the DOS technique. This was applied by hand [12] using twin $0.6 \mathrm{~mm}$ diameter E-glass yarns for stitching the preform panels as through thickness reinforcement. The stitches were inserted in defined steps precisely following the method used to generate the SOS technique. The DOS technique has an altered stitch pattern in comparison with the MLS and SOS techniques; this is particularly apparent in the vertically and horizontally stitched specimens with two columns as is illustrated in the sketch in Fig. 5 which demonstrates the cross section of the DOS stitch pattern.

\subsubsection{Comparison of SOS and DOS techniques versus MLS technique}

The alternative SOS and DOS techniques which have been applied in this work are structurally simpler than the conventionally-used modified lock-stitching technique and of considerable significance is the fact that the theoretical stitch formation does not require any angles to be made in the yarn that are greater than $90^{\circ}$.

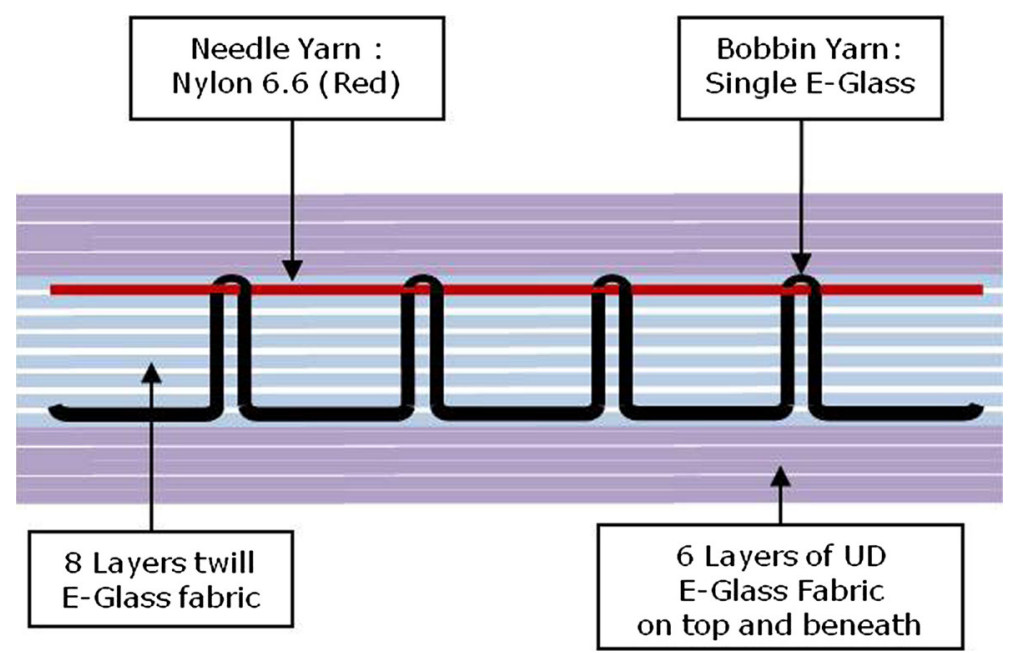

Fig. 3 Schematic drawing of the MLS technique (cross section of the MLS geometry) 


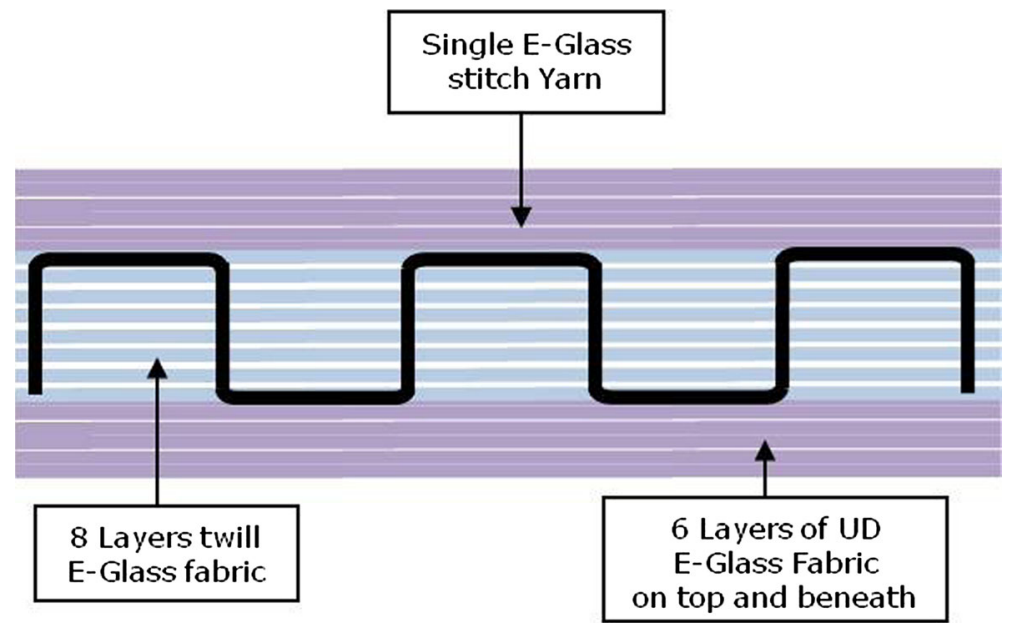

Fig. 4 Schematic drawing of the SOS technique (cross section of the SOS geometry)

The seam is devoid of intra-looping or interlacement, both of which techniques unavoidably introduce small radius curves which reduce the performance of textile threads.

In practice, because of the flexibility of the fabric layers being sewn, the bending of the stitching yarn is further degraded in radius. These orthogonal seams are therefore wellsuited to being generated using advanced stiff fibre yarns.

The main and common fundamental characteristic of SOS and DOS stitch geometries are that an equal space is left between two successive needle entry points and the stitching yarn is laid evenly on both sides of the fabric preform to prevent fabric deformation at the needle penetration points, as occurs when applying the commonly-used stitching methods.

This novel stitching technique generates different stitch geometry; therefore, it positions the stitching fibre on both sides of the fabric and thus the fabric is stabilised equally during stitch insertion.

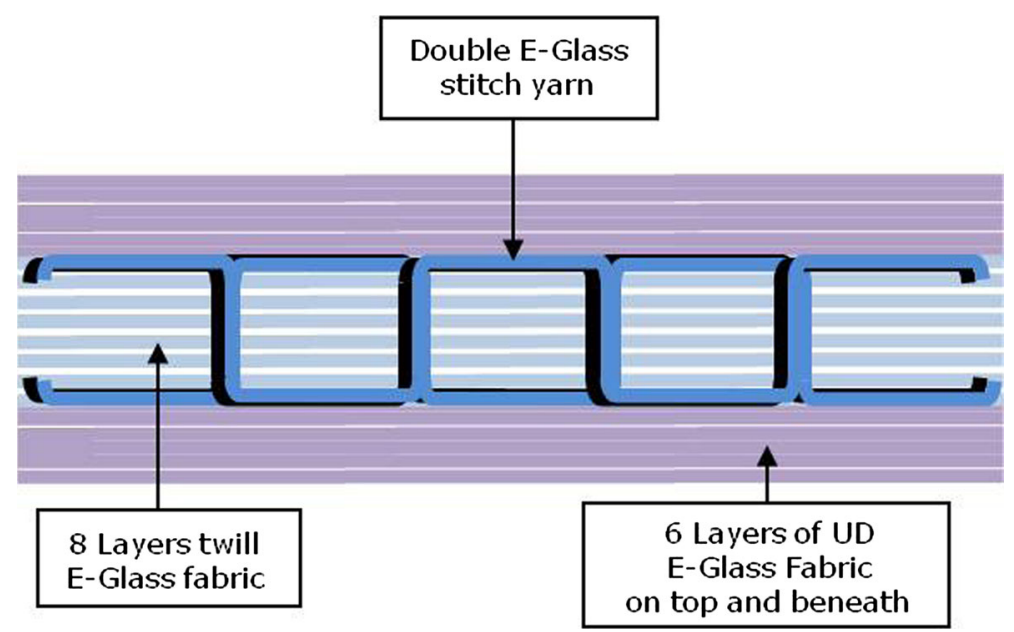

Fig. 5 Schematic drawing of the DOS technique (cross section of the DOS geometry) 
And the most vital difference between these two alternative stitching techniques is when using the different stitch patterns, in particular vertically and horizontally when stitching two column specimens which feature two parallel columns of stitching shown in Fig. 6.

The nylon 6.6 yarn with a fibre density of $1.14 \mathrm{~g} / \mathrm{cm}^{3}$ [27] was supplied by Oxcel and E-glass yarn with a fibre density of $2.54 \mathrm{~g} / \mathrm{cm}^{3}$ [25] was supplied by PPG Textile [28]. All specifications of the stitching yarns are collated in Table 2. The tensile test [29] was examined for both nylon 6.6 and E-glass yarns to compare the mechanical characteristics of the stitching yarns. All mechanical characteristics of the stitching yarns are collated in Table 3.

\subsection{Fabrication of Composite Panels and Test Specimens}

The three steps of vacuuming, resin infusion and curing were carried out on the dry preform panels to fabricate the composite panels. In order that the $63 \mathrm{~mm}$ upper and lower unstitched parts of the test samples should stay separated during and after resin infusion, a non-adhesive Aerovac-A6000 ETFE release film (thickness $20 \mu \mathrm{m}$ ) was laid into the midplane of the preform panel according to the test standard before commencing the vacuuming process. Bisphenol A epoxy resin (Araldite LV 564 with a density of $1.15 \mathrm{~g} / \mathrm{m}^{3}$ ) and hardener (Aradur XB 3486 with a density of $0.95 \mathrm{~g} / \mathrm{m}^{3}$ ), were mixed in the proportion of 100:34 to infuse the preform panel as prescribed by the suppliers, Huntsman International LLC [30]; further preparation before infusion included gas extraction. The composite panels were cured in a Thermo-Scientific Heraeus Oven (T20P) at a temperature of $80{ }^{\circ} \mathrm{C}$ for $8 \mathrm{~h}$ subsequent to the infusion process. Following the curing of the preform panel, the test specimens were cut into separate pieces of $25 \mathrm{~mm}$ width and $125 \mathrm{~mm}$ length. Metal loading hinges with

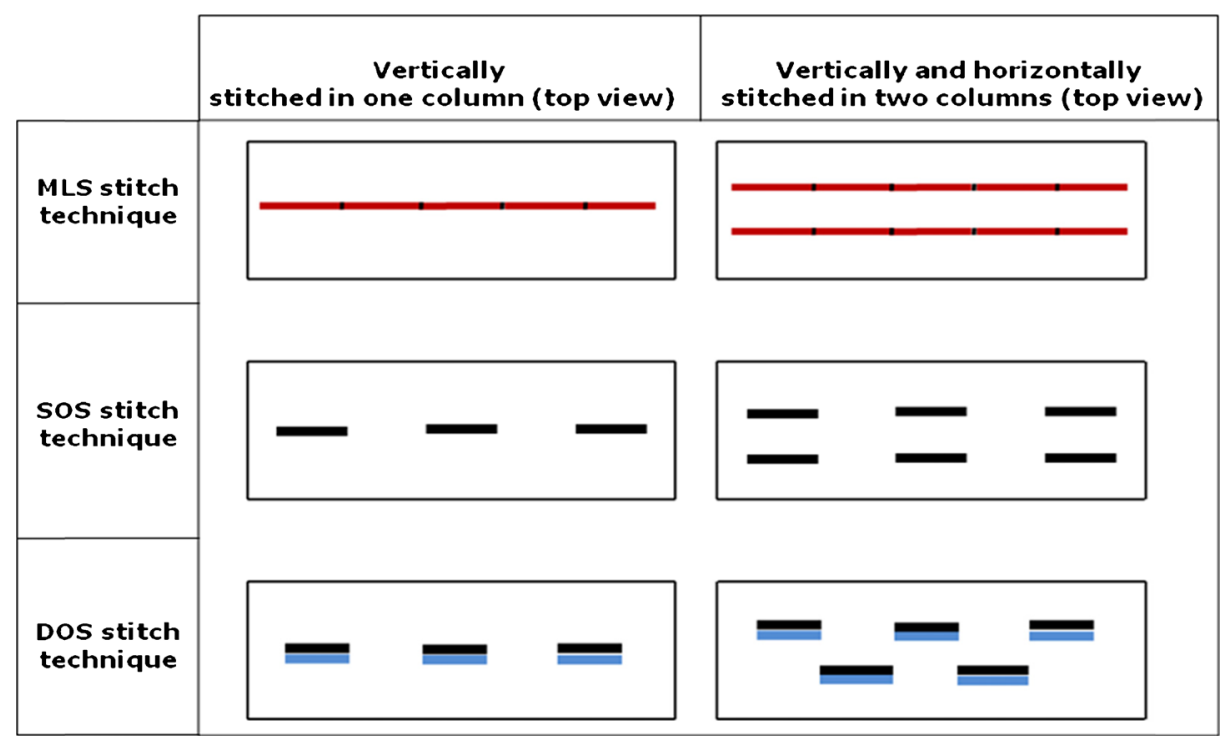

Fig. 6 Overhead view of the schematic patterns of the MLS, SOS, and DOS techniques which are stitched vertically in one column, and vertically and horizontally in two columns 
Table 3 Mechanical characteristics of Nylon 6.6 and E-glass stitching yarns

\begin{tabular}{llcccc}
\hline Stitching yarn & Max. displacement $(\mathrm{mm})$ & Max. load $(\mathrm{N})$ & Strain $(\%)$ & Tenacity $(\mathrm{N} / \mathrm{tex})$ & Modulus $(\mathrm{N} /$ tex $)$ \\
\hline Nylon 6.6 & $84.63( \pm 3.76)$ & $99.53( \pm 2.84)$ & $33.85( \pm 1.50)$ & $1.99( \pm 0.06)$ & $10.06( \pm 0.16)$ \\
E-glass yarn & $6.36( \pm 0.57)$ & $116.64( \pm 12.08)$ & $2.54( \pm 0.23)$ & $0.43( \pm 0.04)$ & $19.81( \pm 0.20)$ \\
\hline
\end{tabular}

dimensions of $25 \mathrm{~mm}$ (width) x $13 \mathrm{~mm}$ (length) were mounted at the end of the test specimens to prepare them for DCB testing.

\section{Test Methods}

The unstitched and stitched composite specimens' Mode I-IFT performances were evaluated by performing DCB tests using an Instron model-8862 machine equipped with a $100 \mathrm{kN}$ load cell. Figure 7 demonstrates a DCB test specimen dimensions and configuration. The test conditions were prescribed by test standard ASTM D5528-01 [26]. The prepared DCB test specimens were held in the tensile testing machine by clamping the loading hinges in the jaws. The test specimens were initially loaded at a constant cross-head speed of $5 \mathrm{~mm} / \mathrm{min}$ for the first $5 \mathrm{~mm}$ of crack extension to provide initial crack growth under stable conditions. The aim of the initial loading is to observe if unsteady crack growth from the insert is apparent. When the crack length reached 3 to $5 \mathrm{~mm}$, the specimens were un-loaded at a constant cross-head speed of $10 \mathrm{~mm} / \mathrm{min}$ and the ends of the cracks were pinpointed to check the difference in crack lengths on both edge sides of the specimens. Subsequently, the DCB composite test specimens were re-loaded at the same loading speed of $5 \mathrm{~mm} / \mathrm{min}$ until the incremental crack growth extended along the entire length of the specimen (50 to $60 \mathrm{~mm}$ ). The test specimens were then un-loaded at a constant cross-head speed of $10 \mathrm{~mm} / \mathrm{min}$ to finish the DCB test. During loading, the onset of delamination crack growths was visually observed and captured using an optical microscope on the edges of the test specimens and crack lengths were noted. When crack growth was observed, at the same time, the load and displacement data were recorded digitally.

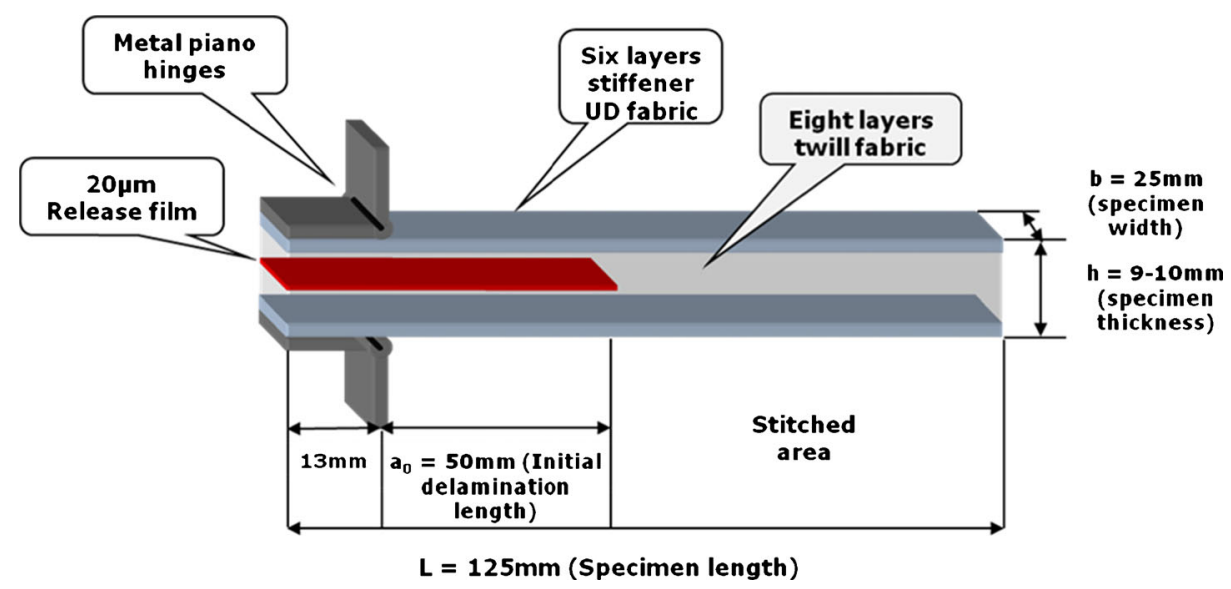

Fig. 7 Configuration and dimensions of DCB test specimens 


\subsection{Calculation of $\mathbf{G}_{\mathrm{IC}}$}

The Mode-IFT, $\mathrm{G}_{\mathrm{IC}}$ - energy release rates were calculated by using modified beam theory (MBT) [26]. The equation is as follows:

$$
\boldsymbol{G}_{\boldsymbol{I}}=\frac{3 \boldsymbol{P} \boldsymbol{\delta}}{2 \boldsymbol{b}(\boldsymbol{a}+|\Delta|)}
$$

Where: $P$ is the Load $(\mathrm{N}), \delta$ is the load point displacement, $b$ is the specimen width, $a$ is the delamination length, and $\Delta$ is determined experimentally by generating a least squares fit plot of the cube root of compliance, $\mathrm{C}^{1 / 3}$, as a function of delamination length. The initiation $\mathrm{G}_{\mathrm{IC}-\mathrm{NL}}$ (NL-Deviation from Linearity) and propagation $\mathrm{G}_{\mathrm{ICP}}$ values were calculated for all composite specimen groups and were used for generating a Delamination Resistance Curve (R-Curve). The R-Curve shows the relationship between the delamination length, $a(\mathrm{~mm})$ and the Mode IIFT, $\mathrm{G}_{\mathrm{IC}}\left(\mathrm{kJ} / \mathrm{m}^{2}\right)$.

\section{Results}

In total sixteen composite specimen groups were prepared for the DCB test and each type of group comprising five specimens to be tested is named in Table 4. These groups of stitched and unstitched test specimens varying in respect of stitch densities and stitching techniques were investigated and compared with each other. The average dimensions of DCB test specimens and their VF (\%) are shown in Table 5.

All the fracture toughness values were calculated by using collected data from DCB testing. The overall test results are presented in the form of load-displacement curves with the help of each particular crack growth point and are displayed in the form of R-Curves with the help of $\mathrm{G}_{\mathrm{IC}}$ values and the delamination length at each particular point. The load-displacement curves and R-curves were classified as UNS-MLS, UNS-SOS, and UNS-DOS. The aim of doing this comparison was to indicate the efficiency of the stitched composites against the unstitched composites, and after eliminating the unstitched specimens, to identify the most effective stitching technique.

Table 4 DCB test specimens, with five different stitch lengths and three different stitch types

Mode I-DCB composite test specimens

\begin{tabular}{|c|c|c|c|c|}
\hline Components in the composite material & \multicolumn{4}{|c|}{ E-glass (Twill and Unidirectional Fabric) / Epoxy } \\
\hline No. of layers & \multicolumn{4}{|c|}{20 Layers (6 UD+8 TWILL+6 UD) } \\
\hline Stitch type & UNS & MLS & SOS & DOS \\
\hline \multicolumn{5}{|l|}{ Stitch lengths } \\
\hline- & A1 $(0)$ & & & \\
\hline $20 \mathrm{~mm}$ vertically in one column & & B1 (20) & G1 (20) & L1 (20) \\
\hline $10 \mathrm{~mm}$ vertically in one column & & C1 (10) & H1 (10) & M1 (10) \\
\hline $5 \mathrm{~mm}$ vertically in one column & & D1 (5) & I1 (5) & N1 (5) \\
\hline $10 \times 10 \mathrm{~mm}$ horizontally and vertically in two columns & & E1 $(10 \times 10)$ & $\mathrm{J} 1(10 \times 10)$ & $\mathrm{O} 1(10 \times 10)$ \\
\hline $5 \times 5 \mathrm{~mm}$ horizontally and vertically in two columns & & $\mathrm{F} 1(5 \times 5)$ & $\mathrm{K} 1(5 \times 5)$ & $\mathrm{P} 1(5 \times 5)$ \\
\hline
\end{tabular}


Table 5 Averaged dimensions of five DCB test specimens with VF (\%)

\begin{tabular}{llllll}
\hline $\begin{array}{l}\text { MODE I-DCB composite } \\
\text { specimens }\end{array}$ & \multicolumn{4}{l}{ Average dimensions and volume fractions } \\
\cline { 2 - 6 } & $\begin{array}{l}\text { Length L } \\
(\mathrm{mm})\end{array}$ & $\begin{array}{l}\text { Width } \mathrm{b} \\
(\mathrm{mm})\end{array}$ & $\begin{array}{l}\text { Thickness h } \\
(\mathrm{mm})\end{array}$ & $\begin{array}{l}\text { Initial delamination } \\
\text { length, } \mathrm{a}_{0}(\mathrm{~mm})\end{array}$ & $\begin{array}{l}\text { Volume fractions } \\
\text { VF }(\%)\end{array}$ \\
\hline Average & 125.6 & 24.8 & 9.7 & 48.2 & 53.1 \\
STDEV & $( \pm 1.1)$ & $( \pm 0.5)$ & $( \pm 0.7)$ & $( \pm 0.7)$ & $( \pm 3.6)$ \\
\hline
\end{tabular}

\subsection{Load-displacement Curves}

UNS; as shown in Fig. 8 the unstitched sample group, A1 (0) has been included as a reference and compared with groups stitched using the MLS, SOS, and DOS techniques. The NL displacement point appears after $4.8 \mathrm{~mm}$. Sample group A1 (0) has the lowest maximum load and displacement, these being approximately $311.2 \mathrm{~N}$ and $12.9 \mathrm{~mm}$ respectively. The load reached a maximum level and remained around this maximum level for a while, and then crack propagation slowly decreased without jumping. The crack growth progressed easily and specimens were delaminated with relative ease through the entire specimen length. Hence the load-displacement curve has a smooth shape. The gradient in the linear region for sample group A1 (0) was bigger than that for all the MLS groups.

MLS; for the MLS groups: B1 [20], C1 [10], D1 [5], E1 $(10 \times 10)$, and F1 $(5 \times 5)$, the NL displacement points are close to each other and appear near the maximum load point. The crack propagation proceeded steadily as shown in Fig. 8, throughout the full specimen length. While the crack behaviour was similar in all the groups made using the MLS technique, the crack propagation behaviour was different from that of the UNS group. All the MLS groups show similarity in behaviour of delamination and crack propagation and in respect of the gradient in the linear region, but amongst these groups, the gradient for sample group F1 $(5 \times 5)$ was smaller than the others. When they reached the maximum load, they rapidly decreased with sharp jumping at each

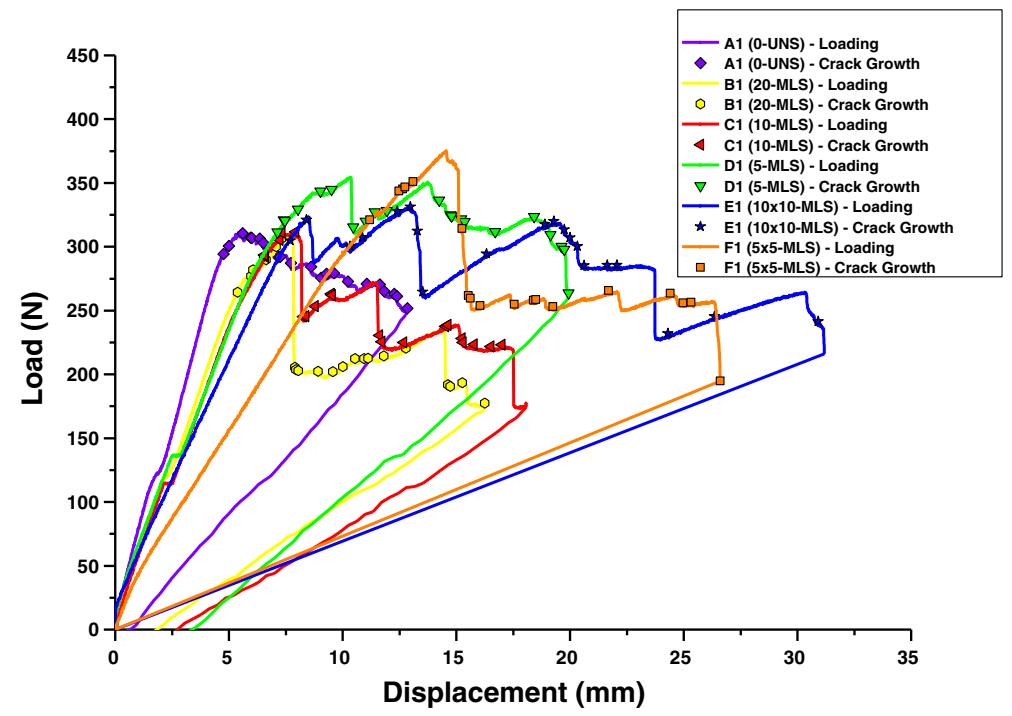

Fig. 8 Typical load-displacement curves for groups of UNS and MLS stitched samples 
individual stitch point. Hence, these groups' load-displacement curves have a characteristic jagged shape and the average maximum load and displacement values were variable. In general, sample groups B1 [20], C1 [10], and D1 [5] which were stitched in one column have low values of load and displacement. Amongst these groups, B1 [20] and C1 [10] have the lowest maximum average load of $311.6 \mathrm{~N}$ with displacements of 16.3 and $17.0 \mathrm{~mm}$ respectively. And group D1 [5] demonstrates the highest maximum average load and displacement. This difference seems to be influenced by featuring the shortest stitch length. However, sample groups E1 $(10 \times 10)$ and F1 $(5 \times 5)$ which were stitched in two columns have high values of load and displacement, and among these two groups; the F1 $(5 \times 5)$ has the highest maximum average load of $375.4 \mathrm{~N}$ with a displacement of $26.6 \mathrm{~mm}$, and it is characterised by having the shortest stitch length and also by the number of columns of stitching in the specimen; this is the densest reinforcement stitching used in this work.

SOS; as shown in Fig. 9, in general, all the SOS groups: G1 [20], H1 [10], I1 [5], J1 (10× $10)$ and $\mathrm{K} 1(5 \times 5)$, the NL displacement points are quite close to each other and appear near the maximum load point. They show similar behaviour in respect of delamination and crack propagation. It can be seen that the load and displacement values increase in line with reducing stitch length and with an increased number of columns of stitches. When they reach a maximum load, they suddenly decrease sharply at each stitching point. Hence, all the SOS groups' loaddisplacement curves exhibit a jagged shape. The gradient in the linear region for all the SOS groups was similar; furthermore, it shows similarity to the UNS composite group. Among sample groups G1 [20], H1 [10], and I1 [5] which were stitched in one column through the specimen length; I1 [5] has the highest maximum average value of $341.9 \mathrm{~N}$ with the value of $14.6 \mathrm{~mm}$ displacement. This performance seems to be influenced considerably by having the smallest stitch length. However, amongst the groups of J1 $(10 \times 10)$, and K1 $(5 \times 5)$ which were stitched in two columns through the specimen length, K1 $(5 \times 5)$ has by a considerable margin the highest value of maximum average load, $365.4 \mathrm{~N}$, with a displacement of $15.6 \mathrm{~mm}$.

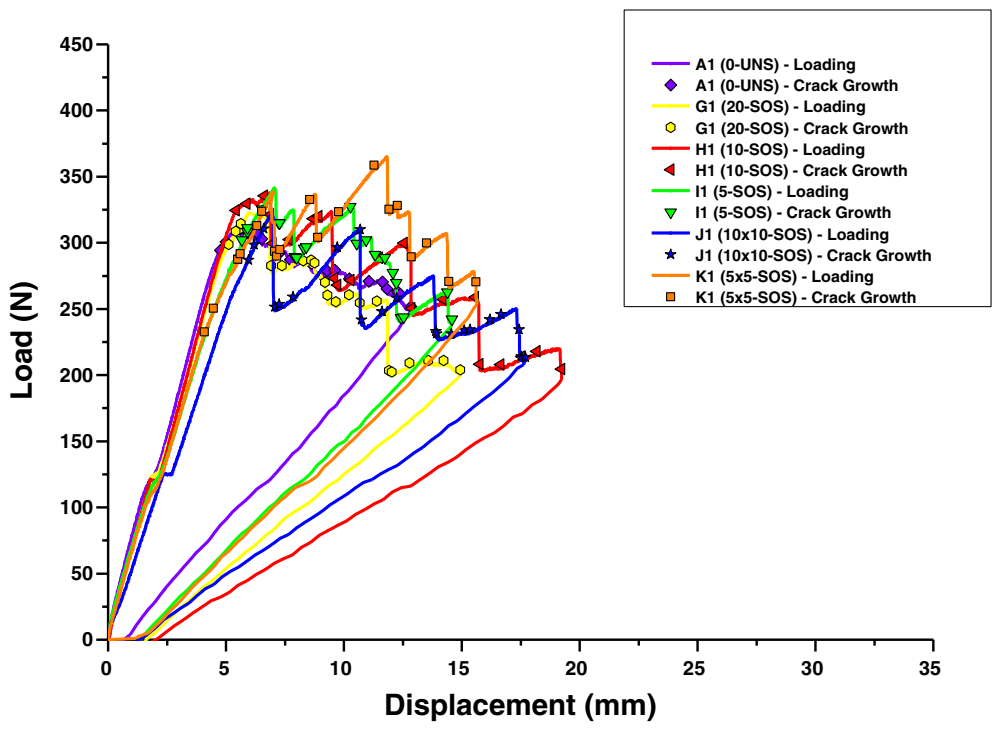

Fig. 9 Typical load-displacement curves for groups of UNS and SOS stitched samples 
DOS; as illustrated in Fig. 10, in general, for the all DOS groups: L1 [20], M1 [10], N1 [5], $\mathrm{O} 1(10 \times 10)$ and $\mathrm{P} 1(5 \times 5)$, the NL displacement points are close to each other and appear near the maximum load point, and test specimens show similarity in respect of their delamination and crack propagation behaviour. When they reached their maximum load, they decreased sharply at each stitching point. Hence, the load-displacement curves for all the DOS groups have a jagged shape. The gradient in the linear region for the L1 [20], N1 [5], O1 (10 × 10), and P1 $(5 \times 5)$ were similar and also show similarity with the UNS composite group. Among all the DOS groups the gradient of M1 [10] in the linear region was smaller than the others. Sample groups L1 [20], M1 [10], and N1 [5] have similar values of maximum average load and displacement, and among these groups, N1 [5] has the highest maximum average load of $323.0 \mathrm{~N}$ with a displacement value of $20.8 \mathrm{~mm}$. The particular characteristic of these three groups is that they were stitched in one column through the specimen length. However, sample groups $\mathrm{O} 1(10 \times 10)$, and $\mathrm{P} 1(5 \times 5)$ were stitched in two columns through the specimen length, and of these, P1 $(5 \times 5)$ has by a considerable margin, the highest value of maximum average load $417.9 \mathrm{~N}$ with a displacement of $27.5 \mathrm{~mm}$. It can be stated that the maximum average load values increase with reducing stitch length and with an increased number of columns of stitches.

\subsection{R-Curves and $\mathrm{G}_{\mathrm{IC}}$ - Energy Release Rates}

UNS; as shown in Fig. 11 the initiation $\mathrm{G}_{\mathrm{IC}-\mathrm{NL}}$ points for the sample group A1 (0) appeared later than the other MLS specimens and the crack propagation $\mathrm{G}_{\mathrm{ICP}}$ was continuous and stable. Therefore, crack growth proceeded relatively easily and specimens were smoothly delaminated throughout the entire specimen length. Hence, group A1 (0) has a low $\mathrm{G}_{\mathrm{ICP}}$ value of $1.82\left(\mathrm{~kJ} / \mathrm{m}^{2}\right)$.

MLS; Fig. 11 gives R-Curves and Fig. 12 illustrates initiation $\mathrm{G}_{\mathrm{IC}-\mathrm{NL}}$ and propagation $\mathrm{G}_{\mathrm{ICP}}$ values. Whilst the $\mathrm{G}_{\mathrm{IC}-\mathrm{NL}}$ values are varied for all the MLS specimens, only the $\mathrm{G}_{\mathrm{IC}-\mathrm{NL}}$ of sample group C1 [10] appeared similar to those of the unstitched sample group A1 (0), yet they still showed higher $\mathrm{G}_{\mathrm{IC}-\mathrm{NL}}$ values than those of $\mathrm{Al}(0)$ group. The $\mathrm{G}_{\mathrm{IC}-\mathrm{NL}}$ values for

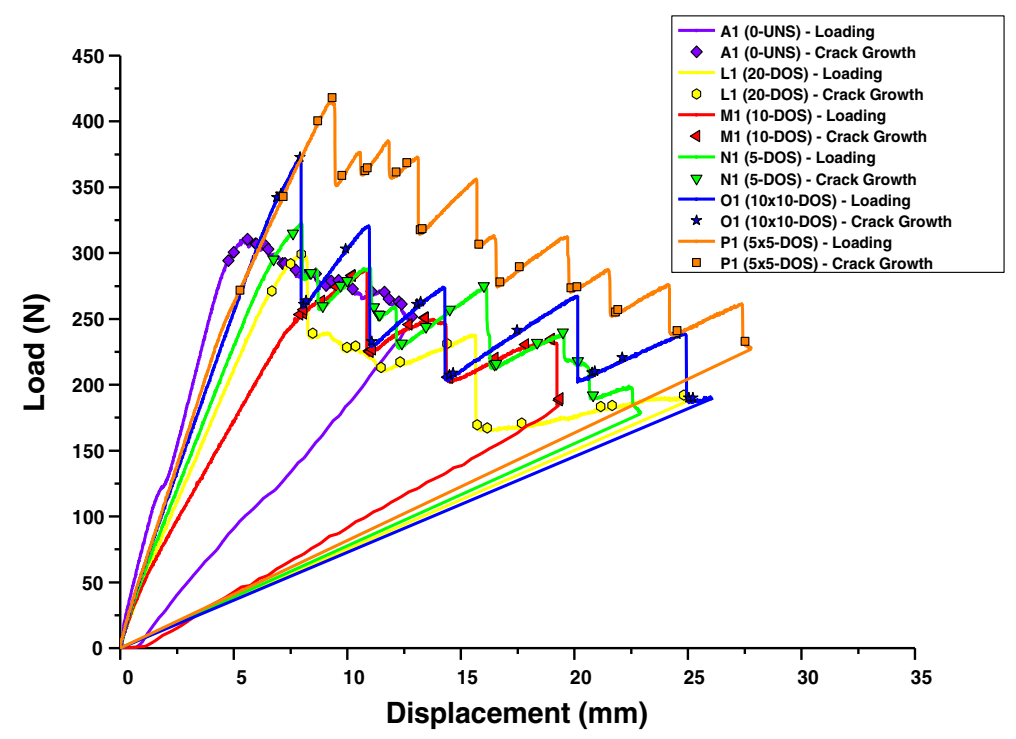

Fig. 10 Typical load-displacement curves for groups of UNS and DOS stitched samples 


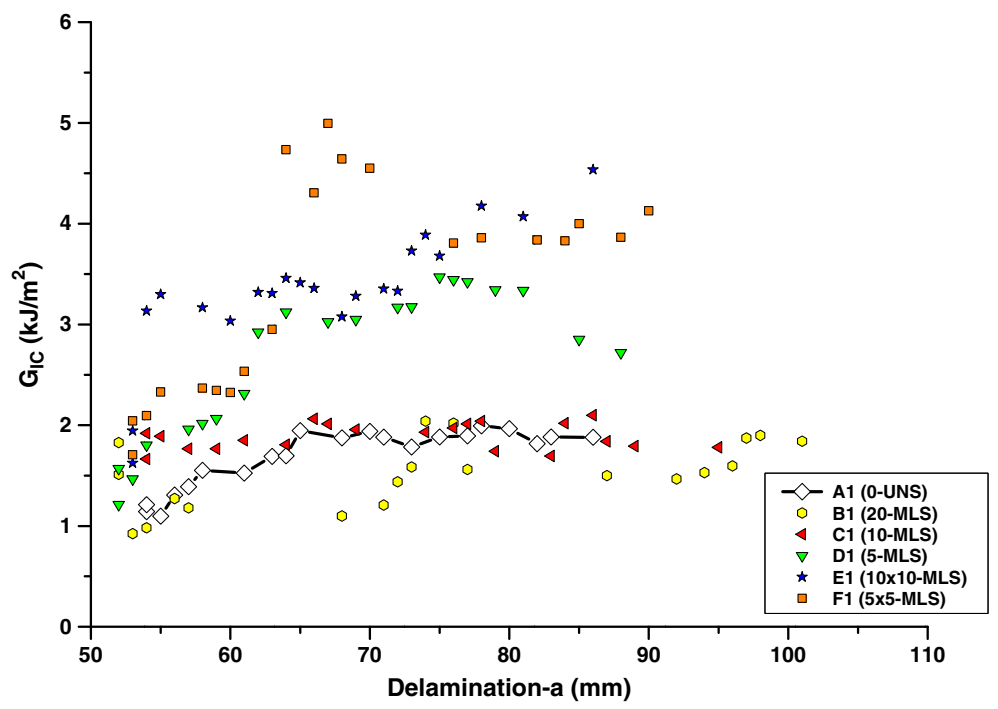

Fig. 11 Typical R-curves for groups of UNS and MLS stitched samples

sample group B1 [20], and D1 [5] appeared similar to one another, likewise, the $\mathrm{G}_{\text {IC-NL }}$ points for sample group E1 $(10 \times 10)$ and F1 $(5 \times 5)$ also appeared similar to one another. Amongst the specimens tested, B1 [20], C1 [10] and D1 [5] which were all stitched in one column, D1 [5] demonstrated the highest $\mathrm{G}_{\mathrm{ICP}}$ figures with the value of $2.81\left(\mathrm{~kJ} / \mathrm{m}^{2}\right)$, by showing gradual crack growth. However, sample group B1 [20] has the lowest $\mathrm{G}_{\mathrm{IC}-\mathrm{NL}}$ and $\mathrm{G}_{\mathrm{ICP}}$ value amongst the all MLS groups, with the value of $1.42\left(\mathrm{~kJ} / \mathrm{m}^{2}\right)$ and $1.67\left(\mathrm{~kJ} / \mathrm{m}^{2}\right)$ respectively, as it was stitched with the longest stitch length $(20 \mathrm{~mm})$. Group D1 [5] is $54.4 \%$ higher than the unstitched group A1 (0) and $68.3 \%$ higher than group B1 [20]. It can be concluded that the concentrated stitch density has improved the Mode I-IFT. Groups of samples E1 $(10 \times 10)$ and F1 $(5 \times 5)$, were stitched in two columns, and both showed gradual crack growth and their $\mathrm{G}_{\mathrm{ICP}}$ values are almost identical to one another. The propagation points of $\mathrm{F} 1(5 \times 5)$ showed a

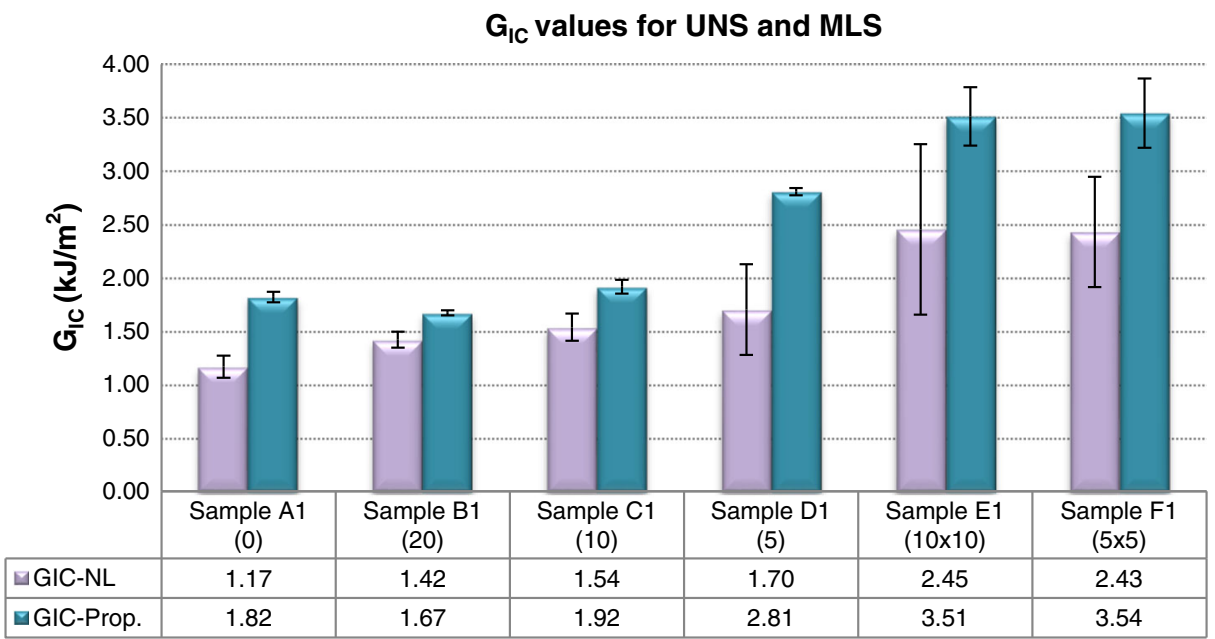

Fig. 12 A comparison of $\mathrm{G}_{\mathrm{IC}-\mathrm{NL}}$ and $\mathrm{G}_{\mathrm{ICP}}$ values for UNS and MLS stitched samples 
higher degree of dispersal and this group has the highest $\mathrm{G}_{\mathrm{ICP}}$ with the value of $3.54\left(\mathrm{~kJ} / \mathrm{m}^{2}\right)$. They produced a better fracture toughness, greater than any of the other MLS groups. F1 (5× 5 ) is $94.5 \%$ higher than the unstitched samples group A1 (0) and $26 \%$ higher than group D1 [5]. It can be concluded that the concentrated stitch density and also the number of columns of stitching have significantly improved the Mode I-IFT. In general, the standard deviation (S.D.) values of initiation and propagation are small. But, in particular sample groups D1 [5], E1 $(10 \times 10)$, and F1 $(5 \times 5)$ show the largest deviations for the initiation values. Table 6 gives the initiation $\mathrm{G}_{\mathrm{IC}-\mathrm{NL}}$ and the average propagation $\mathrm{G}_{\mathrm{ICP}}$ values for the UNS and MLS groups along with the standard deviations (S.D.) and coefficient of variation (C.V.).

The SEM photomicrographs in Fig. 13 shows the cross-section of F1 $(5 \times 5)$ along the crack propagation path of the specimen after testing. This specimen was stitched in two columns with the highest stitch density. As this group has more stitches in two columns than the other groups, it presented the highest fracture toughness value of all the MLS groups. For this heavily stitched specimen, during DCB testing, the nylon 6.6 yarn which was originally on its top surface was pulled down into the body of the laminate by the stitch legs of the E-glass yarn in the through thickness direction. As can be seen in Fig. 13, most stitches remained unbroken, but more fibre damage was created in the midplane of the sample. It can also be seen that there are resin-rich areas at the interlacement points of the stitching yarns on the surface of the specimen and at the separation points of the E-glass yarn's stitching legs on the upper surface of the bottom part of the fractured specimen.

SOS; Fig. 14 gives the R-Curves and Fig. 15 illustrates crack initiation $\mathrm{G}_{\mathrm{IC}-\mathrm{NL}}$ and propagation $\mathrm{G}_{\mathrm{ICP}}$ values. As can be seen in Fig. 14, in general, the crack growths of all the SOS composite samples demonstrate similar behaviour on the R-curve and they have similar $\mathrm{G}_{\mathrm{IC}-\mathrm{NL}}$ initiation values, and also relatively similar $\mathrm{G}_{\mathrm{ICP}}$ propagation values. Among the

Table 6 Mode I-IFT, $\mathrm{G}_{\mathrm{IC}}$ values of UNS and MLS

\begin{tabular}{|c|c|c|c|c|}
\hline $\begin{array}{l}\text { Stitching } \\
\text { techniques }\end{array}$ & $\begin{array}{l}\text { Mode I-DCB } \\
\text { composite } \\
\text { specimen label }\end{array}$ & $\begin{array}{l}\mathrm{G}_{\mathrm{IC}-\mathrm{NL}} \\
\text { initiation } \\
\left(\mathrm{kJ} / \mathrm{m}^{2}\right)\end{array}$ & $\begin{array}{l}\mathrm{G}_{\mathrm{ICP}} \\
\text { propagation } \\
\left(\mathrm{kJ} / \mathrm{m}^{2}\right)\end{array}$ & \\
\hline \multirow[t]{3}{*}{ UNS } & \multirow[t]{3}{*}{ A1 (0) } & 1.17 & 1.82 & Ave. \\
\hline & & 0.10 & 0.05 & S.D. \\
\hline & & 0.09 & 0.03 & C.V. \\
\hline \multirow[t]{15}{*}{ MLS } & \multirow[t]{3}{*}{ B1 (20) } & 1.42 & 1.67 & Ave. \\
\hline & & 0.07 & 0.02 & S.D. \\
\hline & & 0.05 & 0.01 & C.V. \\
\hline & \multirow[t]{3}{*}{ C1 (10) } & 1.54 & 1.92 & Ave. \\
\hline & & 0.13 & 0.06 & S.D. \\
\hline & & 0.08 & 0.03 & C.V. \\
\hline & \multirow[t]{3}{*}{ D1 (5) } & 1.70 & 2.81 & Ave. \\
\hline & & 0.43 & 0.03 & S.D. \\
\hline & & 0.25 & 0.01 & C.V. \\
\hline & \multirow[t]{3}{*}{ E1 $(10 \times 10)$} & 2.45 & 3.51 & Ave. \\
\hline & & 0.80 & 0.27 & S.D. \\
\hline & & 0.33 & 0.08 & C.V. \\
\hline & \multirow[t]{3}{*}{$\mathrm{F} 1(5 \times 5)$} & 2.43 & 3.54 & Ave. \\
\hline & & 0.52 & 0.32 & S.D. \\
\hline & & 0.21 & 0.09 & C.V. \\
\hline
\end{tabular}




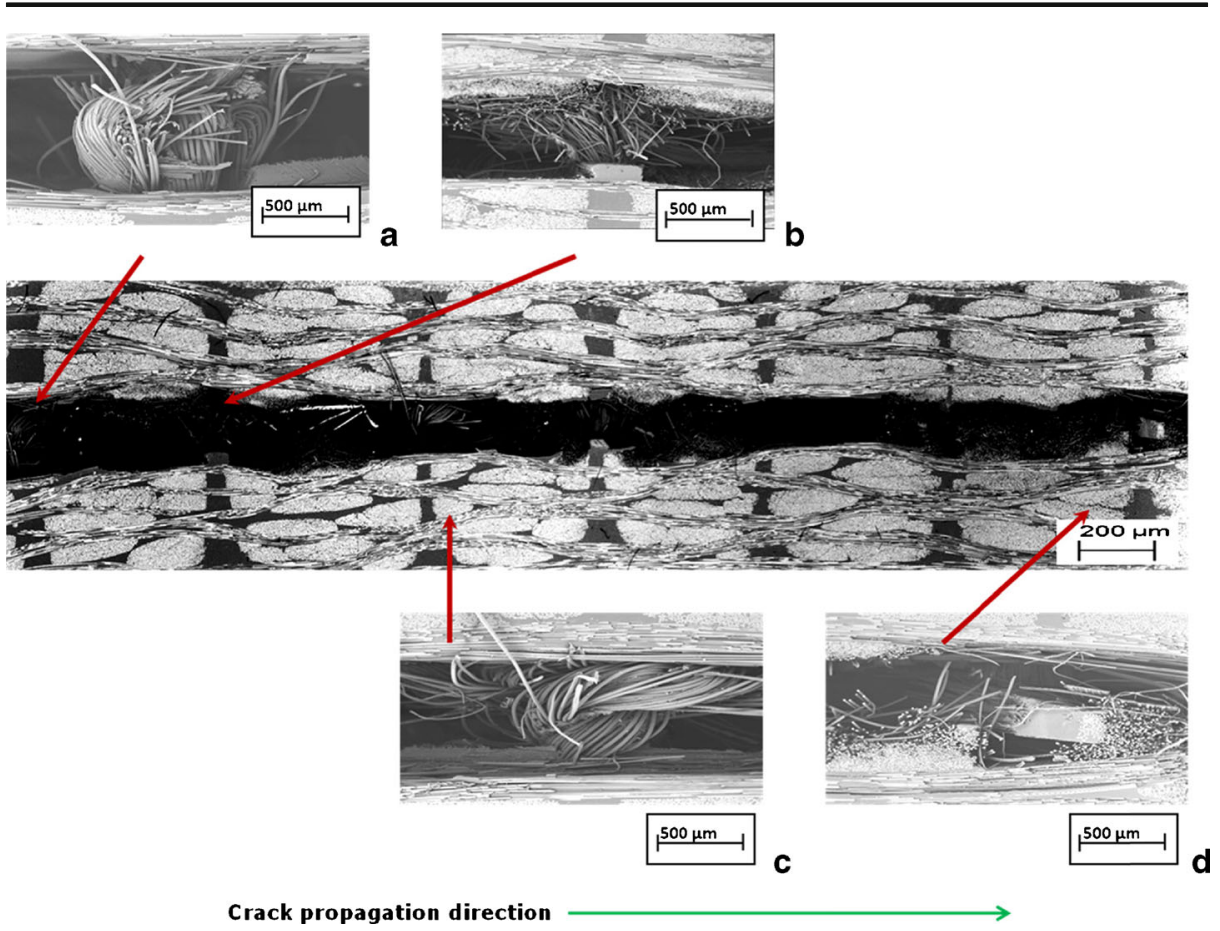

Fig. 13 SEM images of the cross-section along the crack propagation path of sample $\mathrm{F} 1(5 \times 5)$

sample groups G1 [20], H1 [10], and I1 [5] which were stitched in one column through the specimen length, I1 [5] has the highest $\mathrm{G}_{\mathrm{ICP}}$ with a value of $2.18\left(\mathrm{~kJ} / \mathrm{m}^{2}\right)$. Furthermore, amongst the all composite specimen groups to which the SOS technique was applied, G1 [20] has the lowest $\mathrm{G}_{\mathrm{IC}-\mathrm{NL}}$ and $\mathrm{G}_{\mathrm{ICP}}$ with a value of $1.34\left(\mathrm{~kJ} / \mathrm{m}^{2}\right)$ and $1.81\left(\mathrm{~kJ} / \mathrm{m}^{2}\right)$ respectively;

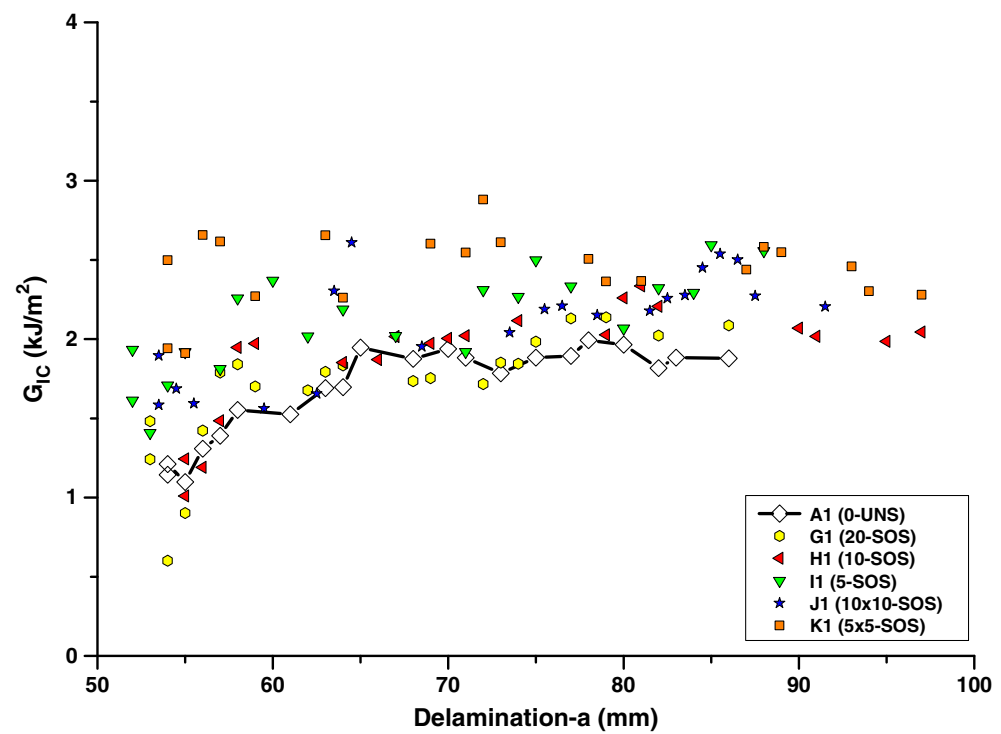

Fig. 14 Typical R-curves for groups of UNS and SOS stitched samples 


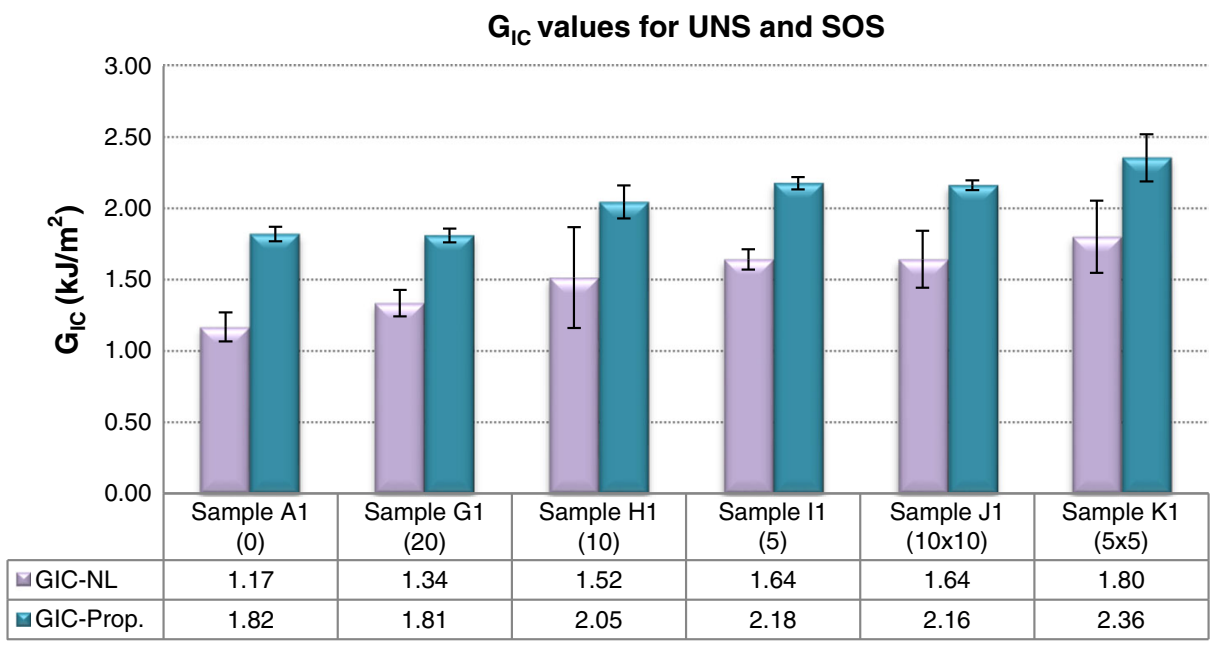

Fig. 15 A comparison of $\mathrm{G}_{\mathrm{IC}-\mathrm{NL}}$ and $\mathrm{G}_{\mathrm{ICP}}$ values for UNS and SOS stitched samples

and it has the longest stitch length at $20 \mathrm{~mm}$. Sample group I1 [5] has $19.8 \%$ higher Mode IIFT values than the A1 (0) group and $20.4 \%$ higher than G1 [20] group which has the longest stitch length. It can therefore be concluded that a higher stitch density bestows much improved Mode I-IFT figures. Likewise, considering the sample groups J1 $(10 \times 10)$ and $\mathrm{K} 1(5 \times 5)$ which were stitched in two columns through the specimen length; K1 $(5 \times 5)$ has the highest $\mathrm{G}_{\mathrm{IC}-\mathrm{NL}}$ and $\mathrm{G}_{\mathrm{ICP}}$ figure with the value of $1.80\left(\mathrm{~kJ} / \mathrm{m}^{2}\right)$ and $2.36\left(\mathrm{~kJ} / \mathrm{m}^{2}\right)$ respectively. The slope of the crack propagation points rises slightly, and the R-curve plateau demonstrates a rise that is smaller than any of the other SOS specimens. Sample group K1 $(5 \times 5)$ is $29.7 \%$ higher in respect of its Mode I-IFT results than the A1 (0) group and $8.3 \%$ higher than the I1 [5] group. It is clear that the high stitch density and also the increased number of columns of stitching give significantly improved Mode I-IFT figures. The S.D. values of initiation and propagation were, in general, very small. But, in particular sample groups H1 [10], J1 $(10 \times 10)$, and K1 $(5 \times 5)$ show the largest deviations for the initiation values. Table 7 illustrates the initiation $\mathrm{G}_{\mathrm{IC}-\mathrm{NL}}$ and the average propagation $\mathrm{G}_{\mathrm{ICP}}$ values for the UNS and SOS groups together with the standard deviations (S.D.) The SEM images in Fig. 16 show a cross section of the crack propagation path of K1 $(5 \times 5)$ after DCB testing. The specimen was stitched in two columns using the SOS technique. As can be seen, delamination continues throughout the main body of the specimen without destroying the stitches. The stitch geometry in the thickness direction remained unaltered. The crack propagation was decelerated by the stitching. But along the crack propagation path, as might be expected, midplane distortion and matrix cracks can be seen. Figure $16 \mathrm{a}-\mathrm{d}$ shows stitching points along the length of the composite specimen.

DOS; Fig. 17 gives R-Curves and Fig. 18 illustrates initiation $\mathrm{G}_{\mathrm{IC}-\mathrm{NL}}$ and propagation $\mathrm{G}_{\mathrm{ICP}}$ values. All the $\mathrm{G}_{\mathrm{IC}-\mathrm{NL}}$ points appeared similar to one another by varying the initiation values for the DOS specimens. As demonstrated in Fig. 17, among the groups comprising L1 [20], M1 [10] and N1 [5] which were all stitched in a single column through the specimen length, L1 [20] and M1 [10] show similar performances in respect of their Rcurves. Conversely, N1 [5] shows more dispersed propagation points than these two groups. In the column-wise comparison, the lowest $\mathrm{G}_{\mathrm{ICP}}$ value belongs to the L1 [20] group and the highest $\mathrm{G}_{\mathrm{ICP}}$ value belongs to the N1 [5] group, being $1.94\left(\mathrm{~kJ} / \mathrm{m}^{2}\right)$ and 2.56 
Table 7 Mode I-IFT, $\mathrm{G}_{\mathrm{IC}}$ values of UNS and SOS stitched samples

\begin{tabular}{|c|c|c|c|c|}
\hline $\begin{array}{l}\text { Stitching } \\
\text { techniques }\end{array}$ & $\begin{array}{l}\text { Mode I-DCB } \\
\text { composite } \\
\text { specimen label }\end{array}$ & $\begin{array}{l}\mathrm{G}_{\mathrm{IC}-\mathrm{NL}} \\
\text { initiation } \\
\left(\mathrm{kJ} / \mathrm{m}^{2}\right)\end{array}$ & $\begin{array}{l}\mathrm{G}_{\mathrm{ICP}} \\
\text { propagation } \\
\left(\mathrm{kJ} / \mathrm{m}^{2}\right)\end{array}$ & \\
\hline \multirow[t]{3}{*}{ UNS } & A1 (0) & 1.17 & 1.82 & Ave. \\
\hline & & 0.10 & 0.05 & S.D. \\
\hline & & 0.09 & 0.03 & C.V. \\
\hline \multirow[t]{15}{*}{ SOS } & G1 (20) & 1.34 & 1.81 & Ave. \\
\hline & & 0.09 & 0.05 & S.D. \\
\hline & & 0.07 & 0.03 & C.V. \\
\hline & H1 (10) & 1.52 & 2.05 & Ave. \\
\hline & & 0.35 & 0.12 & S.D. \\
\hline & & 0.23 & 0.06 & C.V. \\
\hline & I1 (5) & 1.64 & 2.18 & Ave. \\
\hline & & 0.07 & 0.04 & S.D. \\
\hline & & 0.04 & 0.02 & C.V. \\
\hline & $\mathrm{J} 1(10 \times 10)$ & 1.64 & 2.16 & Ave. \\
\hline & & 0.20 & 0.03 & S.D. \\
\hline & & 0.12 & 0.02 & C.V. \\
\hline & $\mathrm{K} 1(5 \times 5)$ & 1.80 & 2.36 & Ave. \\
\hline & & 0.25 & 0.17 & S.D. \\
\hline & & 0.14 & 0.07 & C.V. \\
\hline
\end{tabular}

$\left(\mathrm{kJ} / \mathrm{m}^{2}\right)$ respectively. The propagation values increase progressively and it can be said that the increment depends predominantly on the increase in stitch density. Sample group N1 [5] is $40.7 \%$ higher than the A1 (0) group and $32 \%$ higher than the L1 [20] group. It may be concluded that the higher the stitch density, the higher is the Mode I-IFT figures. Between sample groups $\mathrm{O} 1(10 \times 10)$, and P1 $(5 \times 5)$ which were stitched in two columns, both showed gradual crack growth, but their $\mathrm{G}_{\mathrm{ICP}}$ values differ significantly from one another. The propagation points of group P1 $(5 \times 5)$ showed a higher degree of scatter and these specimens return the highest $\mathrm{G}_{\mathrm{ICP}}$ figure of all the DOS groups with a value of 3.64 $\left(\mathrm{kJ} / \mathrm{m}^{2}\right)$. Sample P1 $(5 \times 5)$ is $100 \%$ higher than the A1 (0) sample and $42.2 \%$ higher than the N1 [5] sample. It should be noted that the conspicuously high $\mathrm{G}_{\mathrm{ICP}}$ value probably derives from the high stitch density, the number of columns and furthermore, particularly depends on the use of the DOS technique. Hence, the P1 $(5 \times 5)$ sample group produced a greater Mode I-IFT than all the other sample groups. The S.D. values for the initiation and propagation values were small in general. But, in particular the $\mathrm{P} 1(5 \times 5)$ group shows the largest deviations for the initiation values. Table 8 shows the initiation $\mathrm{G}_{\mathrm{IC}-\mathrm{NL}}$ and the average propagation $\mathrm{G}_{\mathrm{ICP}}$ values for the UNS and DOS sample groups with their standard deviations (S.D.) and coefficient of variation (C.V.).

The SEM image in Fig. 19 shows the cross section of the crack propagation path of sample P1 $(5 \times 5)$ after testing. The specimen was stitched in two columns with the DOS technique. As the specimen was stitched with a double E-glass yarn and in addition was stitched with the highest stitch density, this specimen group demonstrates improved fracture toughness by resisting delamination. Figure 19a-e shows delamination at each stitch point in the midplane. 


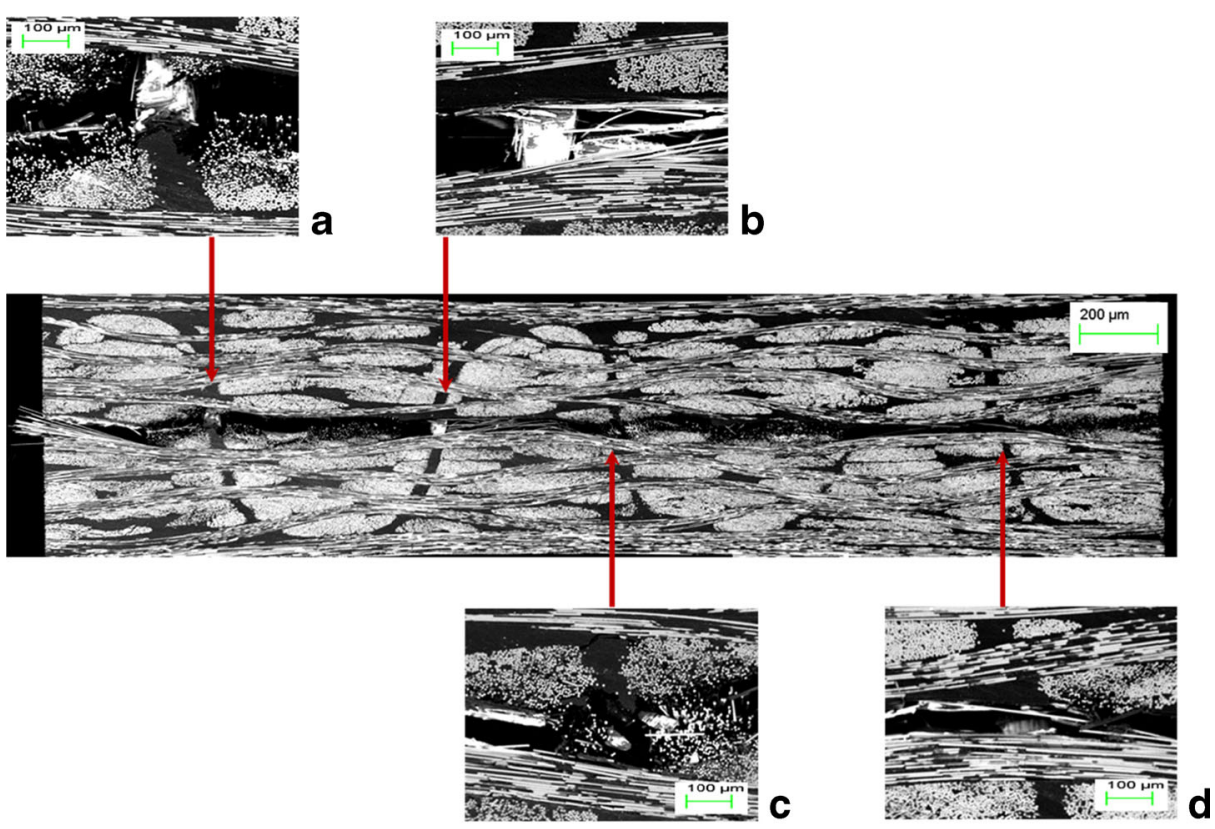

Crack propagation direction

Fig. 16 SEM images of the cross-section along the crack propagation path of sample K1 $(5 \times 5)$

\section{Discussions}

Correlation has been used as a statistical analytical tool to reveal the relationship, if any, between two or more variables. A correlation is a measure of the linear relationship between

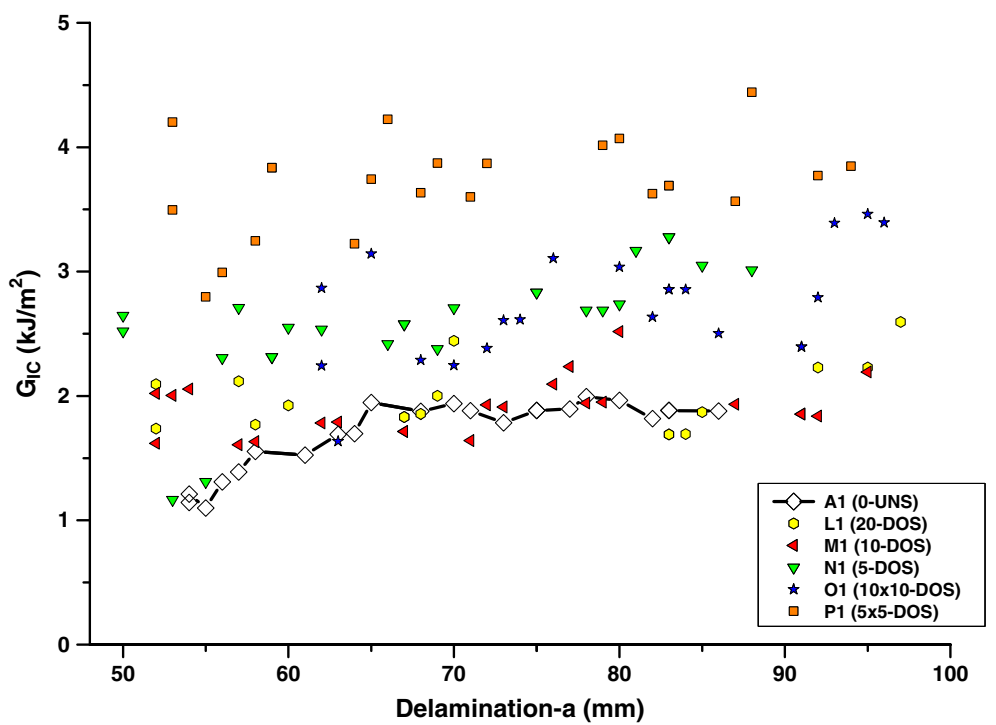

Fig. 17 Typical R-curves for groups of UNS and DOS stitched samples 


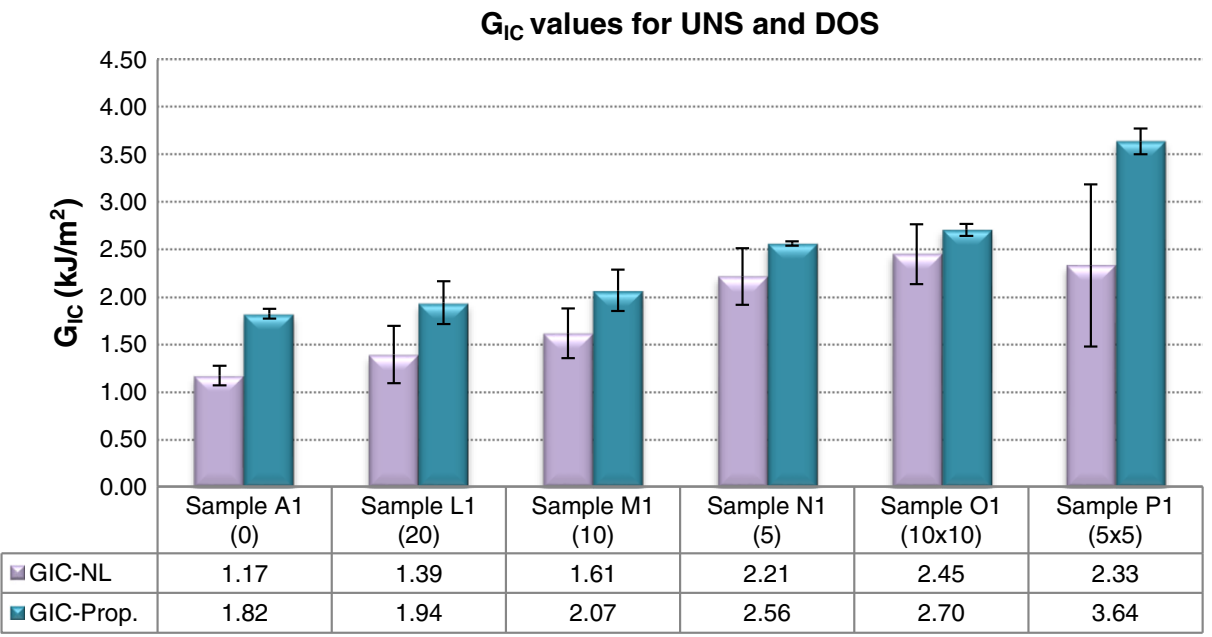

Fig. 18 A comparison of $\mathrm{G}_{\mathrm{IC}-\mathrm{NL}}$ and $\mathrm{G}_{\mathrm{ICP}}$ values for UNS and DOS stitched samples

variables [31] and the correlation coefficient measures the strength and direction of the relationship between two variables as shown in Table 9.

In this study, the UNS group was taken as a reference to help compare the various stitching techniques. The different stitching geometries have been classified as MLS, SOS, and DOS techniques. The differing stitch forms and differing stitching techniques were compared with each other, and detailed examination showed the effect of stitching and also the effectiveness

Table 8 Mode I-IFT, $\mathrm{G}_{\mathrm{IC}}$ values of UNS and DOS

\begin{tabular}{|c|c|c|c|c|}
\hline $\begin{array}{l}\text { Stitching } \\
\text { techniques }\end{array}$ & $\begin{array}{l}\text { Mode I-DCB } \\
\text { composite } \\
\text { specimen label }\end{array}$ & $\begin{array}{l}\mathrm{G}_{\mathrm{IC}-\mathrm{NL}} \\
\text { initiation } \\
\left(\mathrm{kJ} / \mathrm{m}^{2}\right)\end{array}$ & $\begin{array}{l}\mathrm{G}_{\mathrm{ICP}} \\
\text { propagation } \\
\left(\mathrm{kJ} / \mathrm{m}^{2}\right)\end{array}$ & \\
\hline \multirow[t]{3}{*}{ UNS } & A1 (0) & 1.17 & 1.82 & Ave. \\
\hline & & 0.10 & 0.05 & S.D. \\
\hline & & 0.09 & 0.03 & C.V. \\
\hline \multirow[t]{15}{*}{ DOS } & L1 (20) & 1.39 & 1.94 & Ave. \\
\hline & & 0.30 & 0.23 & S.D. \\
\hline & & 0.22 & 0.12 & C.V. \\
\hline & M1 (10) & 1.61 & 2.07 & Ave. \\
\hline & & 0.26 & 0.22 & S.D. \\
\hline & & 0.16 & 0.11 & C.V. \\
\hline & N1 (5) & 2.21 & 2.56 & Ave. \\
\hline & & 0.30 & 0.02 & S.D. \\
\hline & & 0.14 & 0.01 & C.V. \\
\hline & O1 $(10 \times 10)$ & 2.45 & 2.70 & Ave. \\
\hline & & 0.32 & 0.06 & S.D. \\
\hline & & 0.13 & 0.02 & C.V. \\
\hline & $\mathrm{P} 1(5 \times 5)$ & 2.33 & 3.64 & Ave. \\
\hline & & 0.85 & 0.14 & S.D. \\
\hline & & 0.37 & 0.04 & C.V. \\
\hline
\end{tabular}




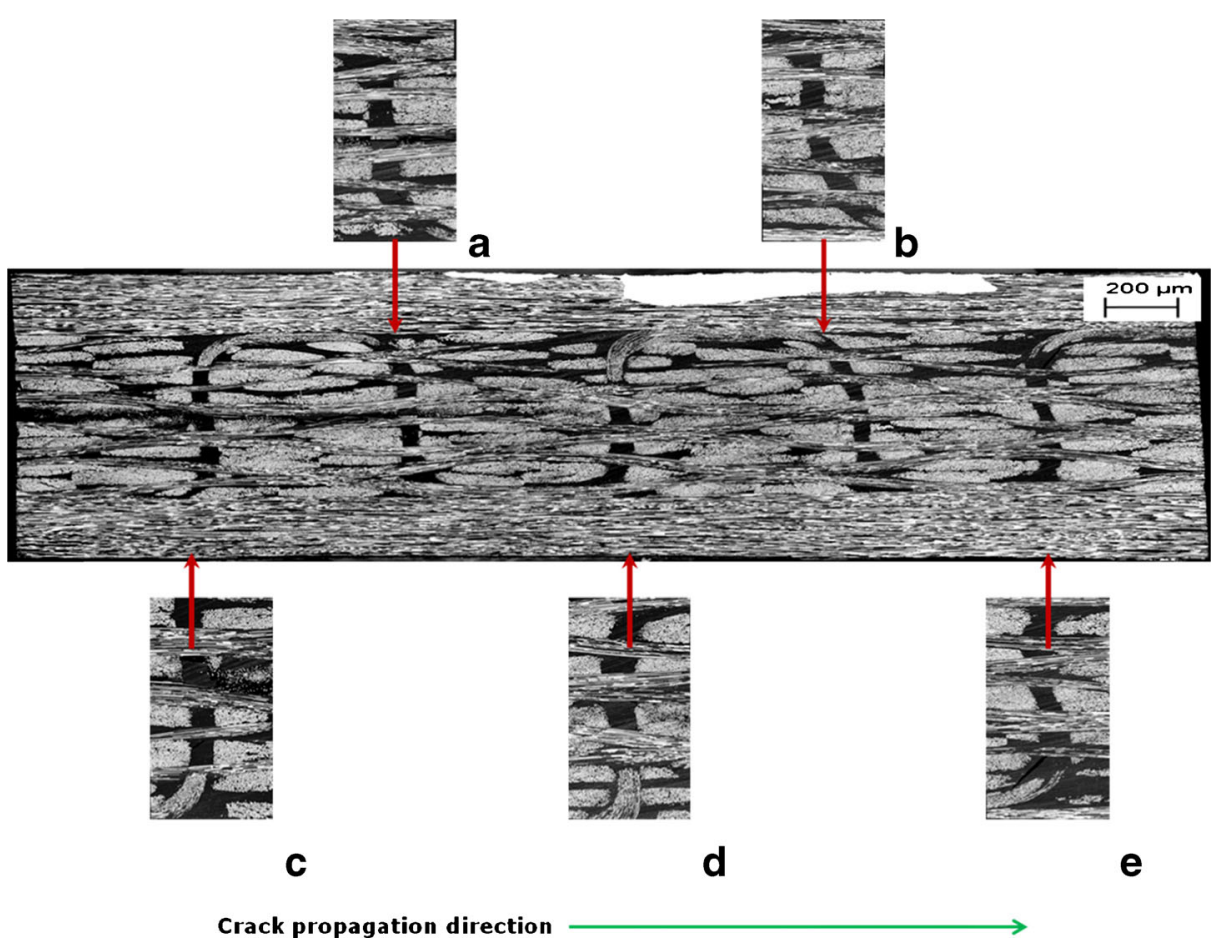

Fig. 19 SEM images of the cross-section along the crack propagation path of sample P1 $(5 \times 5)$

of each stitching technique by observing the IFT individually for Mode I. It was found that the variables, stitching technique, stitch density and the number of columns of stitching, have an effect on the $\mathrm{G}_{\mathrm{ICP}}$ value, and the correlation was further examined to expose the relationship between the variables. To reveal the relationship between the variables, correlation was applied between the number of stitches per unit width and the $\mathrm{G}_{I C P}$ values, and between the stitch density per unit area and the $\mathrm{G}_{\mathrm{ICP}}$ values. To calculate the stitches per unit width (m) and the stitch density per unit area $\left(\mathrm{m}^{2}\right)$, the average dimensions of Mode I-DCB specimens were used. For the DCB specimens the average width, $0.0248 \mathrm{~m}$ and the average stitched area length, $0.0644 \mathrm{~m}$ was used as shown in Table 10 .

\subsection{Correlation Between Stitches per Unit Width and $\mathrm{G}_{\mathrm{ICP}}$}

As shown in Fig. 20 for the UNS-MLS property, a strong relationship $(r=0.8)$ between stitches per unit width and $\mathrm{G}_{\mathrm{ICP}}$ can be detected. However, in particular, the $\mathrm{G}_{\mathrm{ICP}}$ values for the groups in which the stitch type was applied vertically in a single column are more widely spread than those of the other groups. The general trend is that the $\mathrm{G}_{\mathrm{ICP}}$ values increase with an increase in the number of

Table 9 Correlation strength categorisation

\begin{tabular}{lll}
\hline Strength & Negative & Positive \\
\hline Weak & -0.3 to -0.1 & 0.1 to 0.3 \\
Medium & -0.5 to -0.3 & 0.3 to 0.5 \\
Strong & -1.0 to -0.5 & 0.5 to 1.0 \\
\hline
\end{tabular}


Table 10 Average dimensions of Mode I-DCB composite test specimens

\begin{tabular}{llll}
\multicolumn{2}{l}{ Average dimensions } \\
\hline Length (L) & Width (W) & $\begin{array}{l}\text { Initial delamination } \\
\text { length }\left(\mathrm{a}_{0}\right)\end{array}$ & $\begin{array}{l}\text { Stitched area } \\
\text { length }\end{array}$ \\
\hline $125.6 \mathrm{~mm}$ & $24.8 \mathrm{~mm}$ & $48.2 \mathrm{~mm}$ & $64.4 \mathrm{~mm}$ \\
$0.1256 \mathrm{~m}$ & $0.0248 \mathrm{~m}$ & $0.0482 \mathrm{~m}$ & $0.0644 \mathrm{~m}$ \\
\hline
\end{tabular}

stitches per unit width. For the UNS-SOS property, the analysis shows a strong relationship $(r=0.7)$ between stitches per unit width and $\mathrm{G}_{\mathrm{ICP}}$. The general trend is that the $\mathrm{G}_{\mathrm{ICP}}$ values increase with an increase in the number of stitches per unit width as for the MLS technique. Similarly to the previous correlations, a strong relationship $(r=0.8)$ between the number of stitches per unit width and $\mathrm{G}_{\mathrm{ICP}}$ is found for the UNS-DOS property. The general trend is that the $\mathrm{G}_{I C P}$ values increase with an increase in the stitches per unit width as with the MLS and SOS techniques. It should be noted that the reason for the strong relationship between the number of stitches per unit width and the $\mathrm{G}_{\text {ICP }}$ values is convincingly associated with the intensive stitch density, the number of columns of stitching and furthermore, particularly depends on the use of the DOS stitch formation.

\subsection{Correlation Between Stitch Density per Unit Area and $\mathbf{G}_{\mathrm{ICP}}$}

As can be seen in Fig. 21 a very strong relationship $(r=0.9)$ between stitch density per unit area and $\mathrm{G}_{\mathrm{ICP}}$ can be detected for the UNS-MLS property. As a general trend the $\mathrm{G}_{\mathrm{IC}-\mathrm{PROP}}$ values increase with an increase in the stitch density per unit area. The strong relationship between the stitch density per unit area and $\mathrm{G}_{\mathrm{ICP}}$ values for the MLS technique seems to be significantly influenced by high stitch density and by the stitch formation technique. Similarly to the results for UNS-MLS, the calculations for the UNS-SOS property show a very strong relationship $(r=0.9)$ between the stitch density per unit area and $\mathrm{G}_{\mathrm{ICP}}$. It is clear that the strong relationship between the stitch density per unit area and the $\mathrm{G}_{\mathrm{ICP}}$ values of the SOS technique is influenced by the stitch formation technique and is significantly influenced by high stitch density and by the number of columns of stitch lines.

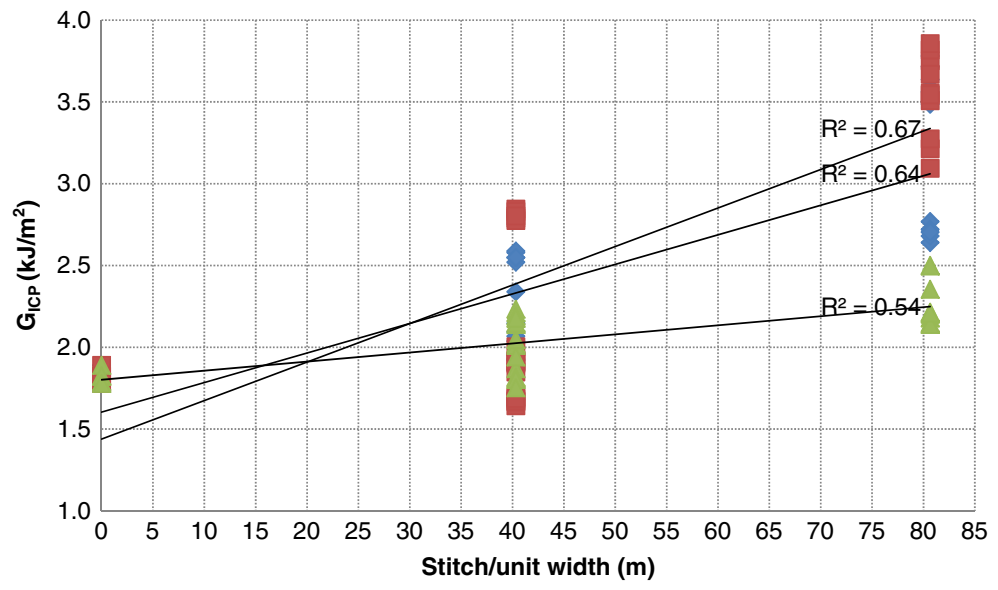

MODE I - (UNS-DOS) MODE I - (UNS-MLS) $\triangle$ MODE I - (UNS-SOS)

Fig. 20 Correlation between stitches per unit width and $\mathrm{G}_{\mathrm{ICP}}$ for UNS-MLS-SOS-DOS samples 


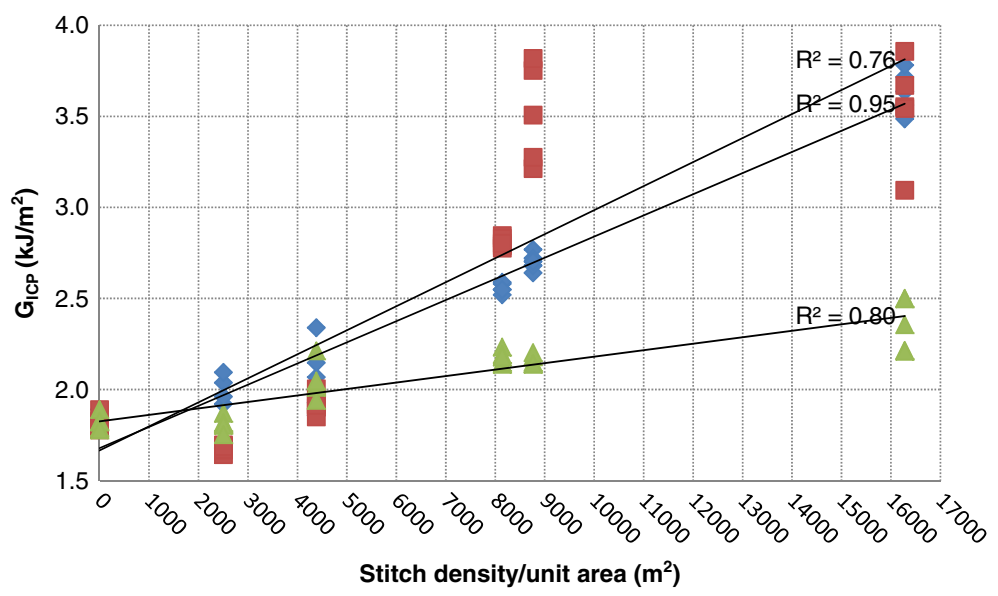

$\diamond$ MODE I - (UNS-DOS) $\square$ MODE I - (UNS-MLS) $\triangle$ MODE I - (UNS-SOS)

Fig. 21 Correlation between stitch density per unit area and $\mathrm{G}_{\mathrm{ICP}}$ for UNS-MLS-SOS-DOS samples

For the UNS-DOS property, a very strong relationship is indicated $(r=1.0)$ between the stitch density per unit area and $\mathrm{G}_{\mathrm{ICP}}$. There is a general trend that the $\mathrm{G}_{\mathrm{ICP}}$ values rise with an increase in the stitch density per unit area, as for the MLS and SOS techniques. It should be noted that the reason for the strong relationship between the stitch density per unit area and the $\mathrm{G}_{\mathrm{ICP}}$ values is convincingly associated with the intensive stitch density, the number of columns of stitching and furthermore, it particularly depends on the use of the DOS stitch geometry.

\section{Conclusions}

This investigation has shown the effect of inserting stitching into textile composites and has identified effective stitching techniques by observing the interlaminar delamination resistance of a number of laminated composite samples. Table 11 compiles an overall comparison of average Mode I-IFT, $\mathrm{G}_{\text {ICP }}$ values which derive from unstitched and stitched groups. As can be seen in Table 11 the UNS sample group A1 (0) returns the lowest average $\mathrm{G}_{\mathrm{ICP}}$ values. The composite sample group K1 $(5 \times 5)$ using the SOS technique demonstrates the second highest average $\mathrm{G}_{\mathrm{ICP}}$ values with a $29.7 \%$ increment over the UNS results. And the composite group F1 $(5 \times 5)$ using the MLS technique has the third highest $\mathrm{G}_{\mathrm{ICP}}$ values with a $50 \%$ increment over the SOS results and a $94.5 \%$ increment

Table 11 Overall comparison of average $\mathrm{G}_{\mathrm{ICP}}$ values for DOS-MLS-SOS-UNS stitched samples

\begin{tabular}{llll}
\hline DOS & MLS & SOS & UNS \\
\hline P1 $(5 \times 5)$ & F1 $(5 \times 5)$ & K1 $(5 \times 5)$ & A1 $(0)$ \\
$3.64\left(\mathrm{~kJ} / \mathrm{m}^{2}\right)$ & $3.54\left(\mathrm{~kJ} / \mathrm{m}^{2}\right)$ & $2.36\left(\mathrm{~kJ} / \mathrm{m}^{2}\right)$ & $1.82\left(\mathrm{~kJ} / \mathrm{m}^{2}\right)$ \\
$2.8 \%$ higher than & $50 \%$ higher than & $29.7 \%$ higher than & The lowest value \\
F1 $(5 \times 5)$ & K1 $(5 \times 5)$ & A1 $(0)$ & \\
$54.2 \%$ higher than & $94.5 \%$ higher than & & \\
K1 $(5 \times 5)$ & A1 $(0)$ & & \\
$100 \%$ higher than & & \\
A1 $(0)$ & & \\
\hline
\end{tabular}


over the UNS results. Of all the stitching techniques used, composite group P1 $(5 \times 5)$ using the DOS technique notably returns higher $\mathrm{G}_{\mathrm{ICP}}$ values with a $2.8 \%$ increment over the MLS technique, and $54.2 \%$ increment over the SOS technique and a $100 \%$ increment over the UNS results. The reason for the high $\mathrm{G}_{\mathrm{ICP}}$ values of the DOS technique, which is greater than for the MLS and SOS techniques seems to be influenced by the stitch formation technique and is significantly influenced by high stitch density and by the number of columns of stitch lines.

- It was found in every case that stitching through thickness reinforcement into composite laminates provides significant resistance against interlaminar cracking (delamination) and generates high $\mathrm{G}_{\mathrm{ICP}}$ values under Mode I loading, the absolute values depending on the stitching technique employed, on the stitch density and on the number of columns of stitching in the composite specimen.

- The orthogonal-stitch (ISO-205) type DOS technique showed the best performance for Mode IIFT. The reason for the excellent $\mathrm{G}_{\mathrm{ICP}}$ capabilities of the DOS stitch form, which is greater than for the MLS and SOS stitch forms, seems to be significantly influenced by the stitch geometry.

- The delamination resistance of the orthogonal-stitch (ISO-205) clearly improves as the stitch density of the reinforcement is increased, as a consequence of reduced stitch length and decreased separation between adjacent seams.

- Among all of the stitching patterns used for Mode I, the $5 \times 5 \mathrm{~mm}$ stitch pattern demonstrated very good performances with a $74.5 \%$ increment over the UNS results. The reason for the high $\mathrm{G}_{\mathrm{ICP}}$ capability of the $5 \times 5 \mathrm{~mm}$ stitch pattern, which is greater than any of the other tested stitching formations under Mode I, seems to be significantly influenced by the high stitch density and by the number of columns of stitching. As the stitching has a good ability to prevent crack growth, short stitch length delays fast crack growths and increases the IFT. Hence, it may be concluded that the $5 \times 5 \mathrm{~mm}$ stitch pattern produces the highest mechanical delamination resistance performance of all the tested stitch formations even though creating more fibre damage by increasing the number of stitch penetration points, producing more fibre distortions around the inserted stitching yarns while piercing the stitching needle into the preform panels, thus causing more resin rich regions in the specimens. These factors tend to compromise the tensile properties of the specimens, however, the inserted stitching thread acts to enhance the tensile properties, so research in this area is rendered complex $[32,33]$.

Open Access This article is distributed under the terms of the Creative Commons Attribution 4.0 International License (http://creativecommons.org/licenses/by/4.0/), which permits unrestricted use, distribution, and reproduction in any medium, provided you give appropriate credit to the original author(s) and the source, provide a link to the Creative Commons license, and indicate if changes were made.

\section{References}

1. Mouritz, A.P., Cox, B.N.: A mechanistic approach to the properties of stitched laminates. Compos. Part A Appl. Sci. Manuf. 31(1), 1-27 (2000)

2. Tong, L., Mouritz, A.P., Bannister, M.K.: 3D fibre reinforced polymer composites. Elsevier (2002)

3. Dransfield, K., Baillie, C., Mai, Y.-W.: Improving the delamination resistance of CFRP by stitching-a review. Compos. Sci. Technol 50(3), 305-17 (1994)

4. Mouritz, A.P., Baini, C., Herszberg, I.: Mode I interlaminar fracture toughness properties of advanced textile fibreglass composites. Compos. Part A Appl. Sci. Manuf. 30(7), 859-70 (1999)

5. Dransfield, K.A., Jain, L.K., Mai, Y.-W.: On the effects of stitching in CFRPs-I. mode I delamination toughness. Compos. Sci. Technol. 58(6), 815-27 (1998) 
6. Jain, L.K., Mai, Y.-W.: On the effect of stitching on mode I delamination toughness of laminated composites. Compos. Sci. Technol. 51(3), 331-45 (1994)

7. Shu, D., Mai, Y.-W.: Effect of stitching on interlaminar delamination extension in composite laminates. Compos. Sci. Technol. 49(2), 165-71 (1993)

8. Velmurugan, R., Solaimurugan, S.: Improvements in Mode I interlaminar fracture toughness and in-plane mechanical properties of stitched glass/polyester composites. Compos. Sci. Technol. 67(1), 61-9 (2007)

9. Solaimurugan, S., Velmurugan, R.: Influence of in-plane fibre orientation on mode I interlaminar fracture toughness of stitched glass/polyester composites. Compos. Sci. Technol. 68(7-8), 1742-52 (2008)

10. Tan, K.T., Watanabe, N., Sano, M., Iwahori, Y., Hoshi, H.: Interlaminar fracture toughness of vectranstitched composites - experimental and computational analysis. J. Compos. Mater. 44(26), 3203-29 (2010)

11. Morales, A.: Structural stitching of textile preforms. Proc. 22nd Int. SAMPE Tech. Conference, (6-8 November). p. 1217-30. (1990)

12. ISO 4915: Textiles-seam types-classification and terminology. International Organization for Standardization. (1991)

13. Ogo, Y.: The effect of stitching on in-plane and interlaminar properties of carbon-epoxy fabric laminates. MSc Thesis, University of Delaware (1987)

14. Mouritz, A.P.: Flexural properties of stitched GRP laminates. Compos. Part A Appl. Sci. Manuf. 27(7), 525-30 (1996)

15. Dransfield, K., Bader, M., Baillie, C., Mai, Y.: The effect of cross-stitching with an Aramid yarn on the delamination fracture toughness of CFRPs. Proc 3rd Int Conf on Deformation and Fracture of Composites. p. 414-23. (1995)

16. Tan, K.T., Watanabe, N., Iwahori, Y.: Stitch fiber comparison for improvement of interlaminar fracture toughness in stitched composites. J. Reinf. Plast. Compos. 30(2), 99-109 (2011)

17. Jain, L.K., Mai, Y.-W.: Determination of mode II delamination toughness of stitched laminated composites. Compos. Sci. Technol. 55(3), 241-53 (1995)

18. Jain, L.K., Dransfield, K.A., Mai, Y.-W.: On the effects of stitching in CFRPs-II. Mode II delamination toughness. Compos. Sci. Technol. 58(6), 829-37 (1998)

19. Sharma, S.K., Sankar, B.V.: Effect of stitching on impact and interlaminar properties of graphite/epoxy laminates. J. Thermoplast. Compos. Mater. 10(3), 241-53 (1997)

20. Sankar, B.V., Sharma, S.K.: Mode II delamination toughness of stitched graphite/epoxy textile composites. Compos. Sci. Technol. 57(7), 729-37 (1997)

21. Mouritz, A.P.: Comment on the impact damage tolerance of stitched composites. J. Mater. Sci. Lett. 22(7), 519-21 (2003). Springer Netherlands

22. Liu, D.: Delamination resistance in stitched and unstitched composite plates subjected to impact loading. J. Reinf. Plast. Compos. 9(1), 59-69 (1990)

23. Kang, T.J., Lee, S.H.: Effect of stitching on the mechanical and impact properties of woven laminate composite. J. Compos. Mater. 28(16), 1574-87 (1994)

24. Sigmatex Ltd. UK, Unit G, Royle Pennine Trading Est., Lynroyle Way, Rochdale OL11 3EX

25. Mallick, P.: Fiber-reinforced composites: materials, manufacturing, and design. CRC Press (1993)

26. ASTM D5528-01: Standard test method for Mode I interlaminar fracture toughness of unidirectional fiberreinforced polymer matrix composites. Annual Book of ASTM Standards, Vol. 15.03. (2002)

27. Hull, D., Clyne, T.W.: An introduction to composite materials. Cambridge University Press (1996)

28. PPG Industries: UK, 400 Guys Run Road Cheswick, PA 15024

29. BS EN ISO 2062: Textiles-Yarns from packages. Determination of single-end breaking force and elongation at break. International Organization for Standardization. (1995)

30. Huntsman International LLC: datashet: two component epoxy paste adhesive. Araldite ${ }^{\circledR}$ 2011, 2011/A, 2011/B. (2007)

31. Field, A.: Discovering statistics using SPSS for windows sage publications. London (2000)

32. Mouritz, A.P.: Fracture and tensile fatigue properties of stitched fibreglass composites. Proc. Inst. Mech. Eng. Part. L J. Mater. Des. Appl. 218(2), 87-93 (2004)

33. Karahan, M., Karahan, N., Ulcay, Y.: Investigation into the tensile properties of stitched and unstitched woven aramid/vinyl ester composites. Text. Res. J. 80(10), 880-91 (2010) 